School of Finance

University of St.Gallen

COMPETITION IN THE CREDIT RATING INDUSTRY: BENEFITS FOR INVESTORS AND ISSUERS

STEFAN MORKOETTER

ROMAN STEBLER

SIMONE WESTERFELD

WORKING PAPERS ON FinANCE No. 2015/05

SWISS INSTITUTE OF BANKING AND FINANCE (S/BF - HSG)

JANUARY 2015

THIS VERSION: FEBRUARY 2016 


\title{
COMPETITION IN THE CREDIT RATING INDUSTRY: BENEFITS FOR INVESTORS AND ISSUERS
}

\author{
Stefan MORKOETTER ${ }^{*}$ ROMAn STEBLER ${ }^{* *}$ SimONE WeSTERFELD ${ }^{* * *}$
}

February 2016

\begin{abstract}
We empirically investigate the benefits of multiple ratings not only at issuance of debt instruments but also during the subsequent monitoring phase. Using a record of monthly credit rating migration data on all U.S. residential mortgage-backed securities rated by Standard \& Poor's, Moody's, and Fitch between 1985 and 2012 (154'600 tranches), our results provide empirical evidence that rating agencies put more effort in rating and outlook revisions when tranches have assigned multiple ratings. Furthermore, we demonstrate that in the case of multiple ratings, agencies do a better job in discriminating tranches with respect to default risk. On the downside, we observe a shift in collateral towards senior tranches and incentives for issuers to engage in rating shopping activities, but find no evidence that rating agencies exploit such behavior to attract more rating business. Our results contribute to the literature on information production of credit ratings and extend the perspective to the monitoring period after issuance.
\end{abstract}

Keywords: $\quad$ Multiple Ratings, Information Production, Structured Finance, Rating Agencies, Residential Mortgage-backed Securities, Rating Shopping

JEL Classification: G14, G21, G24

*University of St. Gallen (mail: stefan.morkoetter@unisg.ch), **University of St. Gallen (mail: roman.stebler@student.unisg.ch), ***University of Applied Sciences Northwestern Switzerland (mail: simone.westerfeld @fhnw.ch). We are grateful to Thomas Nette from Moody's Analytics as well as to Markus Luehe and Mikhail Putkaradze from Fitch Solutions for supporting our research. We thank Martin Brown, Emilia Garcia-Appendini, Zeno Adams, and the participants of the CREDIT 2015 Conference, the 2015 EFMA Annual Meetings, the 2014 Paris Financial Management Conference and the University of St. Gallen Research Seminar for useful comments and suggestions. We further thank Tanja Artiga Gonzalez for helping prepare the data. 


\section{INTRODUCTION}

In the wake of the recent financial crisis, credit rating agencies have been heavily criticized by investors, politicians, and the general public for not putting a red flag on the arising U.S. housing bubble and the subsequent subprime crisis. Yet, only limited research exists on the concrete performance of rating agencies throughout the financial crisis. In this context a rather prominent market segment is U.S. residential mortgage-backed securities (U.S. RMBS): banks mainly used securitization structures to sell off U.S. residential mortgages to investors worldwide and, as we know today, this fueled the U.S. house price bubble. During the months in the run-up of the financial crisis, these securitization transactions became more complex, involving several layers of different securitizations (so called CDO Squared). Why were investors still interested in buying these complex financial products? Because rating agencies acted as their agents and provided a credit rating for each of the issued tranches, most of which were even rated by multiple agencies and still attested unabated credit quality in the beginning of 2008. In an efficient market environment, however, one rating agency should suffice to fulfill the monitoring function on behalf of the investor base. Yet, we know little why issuers, and ultimately investors, are willing to pay for more than one credit rating. What is the benefit of additional ratings from an investor's perspective?

Based on these considerations, we investigate whether multiple ratings benefit investors and analyze how accurately the rating agencies monitored credit quality throughout the 2008 financial crisis. The focus of our research questions is threefold: Does the number of outstanding ratings increase the monitoring effort of each individual rating agency? Do more ratings justify additional costs by incorporating more and also more accurate information? How do issuers benefit from multiple ratings? With our analysis, we shed light on the performance of rating agencies in a bear market and offer valuable insights for investors and regulators for future investment decisions. To our knowledge, we are the first to assess and benchmark the performance of rating agencies focusing on their monitoring activities after tranche issuance.

For the purpose of this paper we define multiple ratings as tranches, which are rated by more than one rating agency (double or triple ratings) as opposed to single rated tranches. We collected data from Standard \& Poor's, Moody's, and Fitch on a total of 154'608 different U.S. residential mortgage-backed securities, which corresponds to a total issuance volume of about 7.51 trillion USD. The rating market for U.S. RMBS follows an oligopolistic market structure 
as it is largely dominated by three rating agencies. We were therefore able to obtain the complete data set of all rated U.S. RMBS tranches, the corresponding characteristics, as well as monthly migration data between January 1985 and July 2012 for our empirical analysis.

We focus our analysis on U.S. RMBS tranches for several reasons. According to the Securities Industry and Financial Markets Association (SIFMA), the mortgage-related U.S. bond market surpassed the market for U.S. corporate bonds in terms of issuance volumes and total amount outstanding in every year over the last two decades, with only one exception in 2014. Even though the financial crisis in 2008 has led to a shrinking of the market, the importance of mortgage-related bonds remained unchanged for the U.S. economy and in most recent years we are seeing increasing issuance volumes again. Representing more than $80 \%$ of mortgage-related bonds in 2015, U.S. RMBS are an important part of this market segment (SIFMA, 2016). ${ }^{2}$ Second, using U.S. RMBS tranches as opposed to other debt related instruments allows us to cover almost the complete rating market as Standard \& Poor's, Moody's and Fitch act as the only providers of credit ratings. We do not notably miss out on any smaller market participants as it is the case for traditional bond markets. Also, in corporate bond markets, investors can rely on additional sources of information to derive information regarding their investments (e.g. investor relations, share price, stock analysts, and credit default swaps). This is not the case for the RMBS markets which are more opaque and investors are much more dependent on information revealed by rating agencies. As a consequence, multiple ratings have a greater impact on information transparency as compared to corporate bond markets, allowing us to better test their importance for investors. Fourth, in our study we assess, among others, the value of multiple ratings from the perspective of investors. For debt instruments it can be difficult to identify the investing party as only few statistics exist. In case of RMBS tranches, however, we know the investor base is quite homogenous as only institutional/professional investors are active. Thus, we can assume that investors also act more uniformly. Finally, U.S. RMBS tranches were at the very heart of the recent financial crisis with many downgrades and defaults in and after 2008. This provides us with a high number of rating events to test our hypothesis. In short, we argue that the U.S. RMBS market provides an almost ideal environment to empirically test the impact of multiple ratings for debt instruments.

\footnotetext{
${ }^{2}$ Note that this figure also includes mortgage-backed securities by government agencies. By end of 2015, total RMBS tranche volume outstanding exceeded USD 7 trillion (USDbn 875 excluding government agencies). In 2015 alone RMBS tranches with a combined volume of USD 1.4 trillion (USDbn 92.5 without government agencies) have been issued (SIFMA, 2016).
} 
Our findings confirm that multiple ratings are indeed of some avail to investors: First, we find empirical proof that rating agencies demonstrate more effort with regard to their monitoring activities in the case of multiple ratings as compared to single-rated tranches. Rating agencies publish more reports and comments and we find that it is up to $11.1 \%$ more likely that a rating agency becomes active as compared to a single-rated tranche. For tranches which eventually entered into default, this probability increases by a factor of about five in the years between 2006 and 2008. Thus, investors get on average more information from each rating agency compared to a less competitive situation (single-rated tranches). Second, we show that rating agencies not only publish more, but also more accurate information in case of multiple ratings as average default prediction accuracy is significantly higher compared to single-rated tranches.

On the other hand, we document that issuers benefit from multiple ratings in the form of lower refinancing cost by allocating additional collateral to senior tranches, ultimately impeding the overall quality of these tranches. As rating agencies appear to be oblivious to this sort of behavior, the shift of assets towards senior rating classes materializes negatively for investors. Moreover, we find that disagreement between rating agencies (as measured by the numerical notch difference of two ratings on the same tranche i.e. the 'rating gap') increases over a tranche's lifetime. On average the predicted rating gap widens by a factor of about ten during (or 2.66 rating notches) the first three years after issuance. With regard to the individual performance of rating agencies, we document that Moody's provides on average the most pessimistic credit assessment at issuance, a pattern that remains over a tranche's lifetime. In addition, we report a rather devastating result with regard to the overall performance of securitization transactions: Out of the 154'608 individual tranches, 49'022 (or 31.7\% of the total sample) defaulted at one point in time, peaking at 74.1\% for the tranches issued in 2007 (13'030 tranches out of 17'597 issued).

Based on these findings, our paper contributes to the literature on information production of credit ratings, most notably by extending the prevalent, rather static 'at issuance'-perspective to the monitoring period following the initial debt placement. We find empirical proof for the information production hypothesis (e.g. Cantor \& Packer, 1997) in a dynamic environment. We argue that by restricting its focus to the point of issuance (e.g. Skreta \& Veldkamp, 2009; Bolton et al., 2012) existing empirical research underestimates the incentives for rating shopping, which become more pronounced throughout a tranche's lifetime as rating divergence increases along the maturity structure. Finally, we extend existing research by benchmarking the relative performance of rating agencies against each other during the monitoring period (e.g. Livingston, 1999). Our results bring good news for investors: They benefit from multiple ratings due 
to increasing default accuracy. Issuer in turn benefit from multiple ratings due to increasing tranche sizes of senior notes resulting in lower refinancing cost. From a regulatory perspective, we provide empirical evidence that a multiplicity of ratings reduces information asymmetries and lowers overall industry opaqueness. Additional ratings serve to increase market transparency and regulators should therefore support initiatives to foster competition between rating agencies.

The remainder of this paper is organized as follows: Section 2 provides an overview of existing literature on information efficiency of multiple ratings and develops the hypotheses based on a framework linking multiple ratings to rating agencies' monitoring activities. Section 3 introduces the data sample and describes the applied methodologies. The empirical results are presented in Section 4. Section 5 discusses potential incentives for issuers to solicit multiple ratings and particularly addresses the concept of rating shopping. Our paper concludes with Section 6 .

\section{Multiple CREDit RATINGS AND MONITORING ACTIVITY}

Asymmetric information is an important characteristic of the securitization market, where products exhibit complex architecture and information about the underlying credit portfolio is highly opaque. Three key market participants can be identified: issuer (who works closely with the underwriter, typically an investment bank), investor and credit rating agency. The issuer structures the transaction via a special purpose vehicle (SPV) in order to sell tranches of different maturity and credit quality to investors. In this process, issuers mandate and pay credit rating agencies to assess the credit quality of each tranche and assign a corresponding credit rating. In reliance on this assessment, investors finally buy the tranches based on their individual risk preferences. As a result of this market structure, the balance of information is typically skewed towards the issuer of a security and the market information function of credit rating agencies constitutes a key factor as due diligence is usually delegated to them by investors (e.g. Diamond, 1984). Thus, the solicitation of rating agencies represents a form of agency costs to mitigate the information asymmetry in the principal-agent relationship between issuer (agent) and investor (principal). Given the assumption that credit ratings from different rating agencies can be considered as substitutes, efficient management of agency costs would imply to assign a single rating agency to assess the credit quality of a securitization tranche or deal to avoid duplication 
of effort. Reality, on the other hand, shows that $72.2 \%$ of tranches in our sample are rated by more than one rating agency and that the fraction of multiple-rated tranches has increased substantially during the past decades. Ratings are typically assigned at issuance. It is not common that ratings are solicited at a later stage and we also do not observe such a pattern in our data sample. However, it can happen that during a tranche lifetime the rating of one or more agencies is withdrawn. It is typically the issuer who terminates the contract, however, rating agencies normally cease their monitoring activities once the tranche is in a default stage. Regarding the transparency among credit rating agencies, they are aware of the increased likelihood of dualor triple-coverage. Yet, the issuer is not required to disclose whether he has solicited other rating agencies for the same transaction nor is the issuer required to disclose any information regarding his dialogue and business relationships with credit rating agencies. Preceding the issuance each mandated rating agency publishes, in agreement with the issuer, a so called pre-sale report, which is used by the issuer to promote the issuance among investors. Thus, rating agencies are at this point aware of potential additional, publicly disclosed ratings. In a letter to the U.S. Securities and Exchange Commission (SEC) Moody's disclosed its own research regarding 44 residential mortgage-backed securitizations, for which Moody's ratings were not publicly disclosed but for which the issuer had initial discussions with Moody's. The rating agency outlines that their ratings would have resulted in significantly lower outcomes than the ratings of the agencies which were eventually mandated (Moody's Investors Service, 2007). Rating methodologies applied by the three major rating agencies differ substantially, which may at least partially explain differences in assigned ratings in the case of multiple coverage. Moody's has long relied on rating models driven by an expected loss (EL) approach as opposed to the rating models applied by its competitors S\&P and Fitch that focus primarily on probabilities of default (PD). Information relating to the modelling of the cash flow analysis is not disclosed by the rating agencies. Fender and Kiff (2005) explore the impact of differences in methodologies across rating agencies for senior tranche rating outcomes. For example, other things being equal, an EL approach may be more favorable to large senior tranches compared to a PD approach, and less favorable towards more junior tranches that tend to be of thinner size. Against the background of information asymmetries between issuer, rating agency and investors, they argue that rating model arbitrage is a theoretical possibility.

There are two distinct aspects that can be associated with the market information function of credit ratings: At the time of issuance, rating agencies perform a signaling function to investors and regulators, assessing the credit quality of tranches' underlying portfolio of assets in 
order to help issuers selling their securitization tranches to investors. This delegation of monitoring by investors is not limited to the initial issuance of a tranche. Credit rating agencies rather maintain an important monitoring function and further act as agents on behalf of investors: They regularly evaluate the tranche's credit quality and adjust their ratings if necessary. ${ }^{3}$ Such a review process can either result in an upgrade (in case the credit quality has improved), a downgrade (in case the credit quality has deteriorated) or result in no action (in case the credit quality has not changed at all). Rating agencies also publish so-called 'outlook reports', which incorporate a positive or negative outlook but do not trigger any rating events. The outcomes of these monitoring efforts are important information sources for investors, since it allows them to keep a check on their own risk-return balance and to control whether or not the tranches are still in line with the individual investment policies. Rating changes also have a severe impact on the price of tranches with downgrades (or upgrades) typically leading to a decrease (or increase). In short, the performance of rating agencies is not limited to the assessment of credit quality at the point of issuance, but remains important throughout the whole maturity structure of a product.

Several studies from the corporate bond market investigate potential explanations for multiple ratings. In an early publication, Hsueh \& Kidwell (1988) analyze why borrowers obtain more than one credit rating. Using a large sample of new-issue general obligation bonds sold between 1976 and 1983, they empirically test the impact of a municipality's decision to acquire a second rating for split- and non-split-rated bonds on new issue borrowing cost. The findings suggest that two credit ratings provide additional information and that split-rated bond issues account for reduced borrowing costs. Cantor \& Packer (1995) explore whether the motivation for getting additional ratings is driven by regulatory considerations. However, they only find little evidence in support of their hypothesis. Only in the case of junk bonds, the availability of a third opinion enables some borrowers to escape the speculative grade zone into investment grade territory. In a later paper, Cantor \& Packer (1997) use issuer-level ratings from the year 1994 in an attempt to understand the motivation for obtaining a third rating. They consider information efficiency, rating shopping, and certification effects, but fail to find evidence that the use of a third rating is motivated by any of these considerations, although they demonstrate that the third rating is systematically more optimistic.

Inspired by the recent financial crisis and the allegations against credit rating institutions, several scholars put forward theoretical models on the rating shopping phenomenon. Rating

\footnotetext{
${ }^{3}$ In the following, we will hence refer to the time between issuance of a security and the legal maturity date as the monitoring period.
} 
shopping refers to an issuer's practice of engaging in a dialog with multiple rating agencies but mandating only those which offer the most favorable outcomes. In this process, issuers are in a constant exchange with rating agencies to optimize the transaction structure from their perspective, without revealing this dialog to investors. Skreta \& Veldkamp (2009) present a framework where incentives for rating shopping increase as the complexity of the products increases. In one of the most recent publications, Bolton et al. (2012) focus on the conflicts of interest in credit rating agencies by modeling competition among agencies with three different sources of conflicts: (i) understating risk to attract business, (ii) issuers' ability to attract only the most favorable rating, and (iii) the overreliance on ratings by some investor clienteles. Based on their model, the authors conclude that competition can reduce information efficiency, as it facilitates rating shopping and that ratings are more likely to be inflated during booms or when investors are more trusting. Sangiorgi, Sokobin \& Spatt (2009) develop a theoretical model of rating shopping and explore biases in ratings conditional upon heterogeneity across issuers in the extent to which different rating authorities agree.

Empirical evidence documenting this effect is, however, rather weak both in corporate finance and securitization markets. By focusing predominantly on ratings at issuance, empirical studies typically find only limited evidence that issuers engage in rating shopping behavior. Jewel \& Livingston (1999) investigate whether ratings differ systematically across rating agencies. They examine a very large database with monthly observations of bonds and bond ratings over a five-year time period. The results show the average Fitch rating to be significantly better than Moody's and S\&P ratings, but the effect disappears once they restrict their sample to bonds rated by all three rating agencies. However, Fitch ratings serve as a tiebreaker in cases where S\&P and Moody's fail to reach consensus. The authors also examine whether rating shopping takes place but cannot find any evidence to support this hypothesis. Bongaerts et al. (2012) explore the economic role of credit rating agencies in the corporate bond market by considering three existing theories about multiple ratings: information production, rating shopping and regulatory certification. However, using differences in rating composition, default prediction and credit spread changes, their evidence only supports regulatory certification. The authors conclude that marginal, additional credit ratings are more likely to occur because of regulatory purposes, and seem to matter primarily for them, but do not seem to provide significant additional information related to credit quality. Bannier \& Tyrell (2006) focus on reputation and competition among rating agencies. By proving that under certain conditions, public rating announcements and private information collection may be complements rather than substitutes, 
they argue that rating agencies may spark off a virtuous circle that increases information precision and raises market efficiency. The study also addresses the difference between solicited and unsolicited ratings and the problem of institutional investors.

Overall, recent literature provides only limited empirical evidence to explain the existence of multiple credit ratings. A potential explanation for the lack of compelling proof might be seen in the strong focus on the signaling function of credit ratings by prevalent literature. Related empirical work so far falls short of including the entirety of rating agencies' monitoring activities and is limited to a rather static 'at issuance' perspective. Little is known of how ratings migrate after tranche issuance and why issuers solicit and pay for multiple ratings not only at issuance but also during the monitoring phase of an asset's term. This paper therefore strives to extend the existing literature on multiple ratings by explaining its existence against the background of monitoring activities following the issuance of securitization tranches. In the following, we will focus our attention on the information production hypothesis (e.g. Cantor \& Packer, 1997) as the prevailing theory in the established literature on the existence of multiple ratings and apply it to a holistic framework.

In contrast to Bongaerts (2012), we dedicate the first part of this paper to the benefits of multiple ratings from the investor's point of view. According to the information production hypothesis, more ratings reduce uncertainty about the underlying credit quality of a security. As investors are adverse to uncertainty, issuers may apply for additional ratings due to the demand for increased information production. Investors are interested in additional information, since it allows them to better assess the credit quality of the underlying debt instruments. Rating agencies may also apply different models or specialize in evaluating particular drivers of default and might thereby develop comparative advantages to justify their existence. Thus, the advantageous effect of rating agencies' different perspectives is expected to provide additional information on the uncertainty associated with credit quality and default probabilities. An additional rating in agreement with the existing rating would reduce credit quality uncertainty, whereas a difference in credit ratings might indicate a higher level of uncertainty, e.g. due to increased opaqueness of underlying assets. But does this argumentation really pay off for investors? Do additional ratings really lead to more and better information for investors?

We argue that competition between rating agencies is more intense during the monitoring period in case of multiple ratings: Since their activities are directly benchmarked to their peers', rating agencies are induced to show more effort with regard to their monitoring obligations than 
observed for single-rated tranches. Consequently, we hypothesize that multiple ratings lead to more activity at the level of each individual rating agency. More activity or effort in turn can be interpreted as more information production:

Proposition 1: $\quad$ Monitoring effort is higher for multiple-rated tranches compared to singlerated tranches.

So far, we were only concerned about the amount of information being produced. However, more information does not necessarily correspond to better information. Investors delegate their monitoring activities to credit rating agencies in order to get a most accurate understanding of the underlying credit quality. Credit quality in turn is measured by default probabilities. Thus, we argue in the following that empirical evidence for the information production hypothesis should also be related to the level of accuracy achieved by rating agencies. The ultimate measure to benchmark accuracy of rating agencies is of course how good they are in predicting the default of debt instruments, not only at issuance but also throughout the whole lifetime of a debt instrument. Thus, to assess default prediction accuracy of rating agencies it is important to include the complete monitoring period and continuously control for credit rating agencies' ability of reassessing credit risk. In addition, rating processes in structured finance diverge significantly from those in the corporate bond market. Unique features are the limited accessibility of rating tools used by the agencies, the different methodologies used and the close cooperation between agency and issuer during the negotiation phase. ${ }^{4}$ In the case of multiple ratings, investors already benefit from the heterogeneity of rating processes and models applied by different agencies. If the presence of rivals induces rating agencies to demonstrate more diligence with respect to their monitoring obligation, we argue that multiple ratings should also lead to higher accuracy of predicting tranche default for each individual rating. Moreover, we would expect this pattern to be traceable over different subsample periods and tranche characteristics:

Proposition 2: $\quad$ Rating classification accuracy is higher for multiple-rated tranches compared to single-rated tranches.

\footnotetext{
${ }^{4}$ The latter has been heavily criticized in the recent past by politicians and regulatory authorities. We do not intend to discuss independency issues of rating agencies in this context; however, we proceed with the assumption that the relationship and exchange between rating agencies and issuers is very close and thereby impacts information efficiency.
} 
While both of these propositions focus on the advantages of multiple ratings from an investor's point of view, we also consider implications on the sell-side of the transaction. Multiple ratings are already frequently used both in RMBS transactions as well as structured finance in general. More than two thirds of tranches in our sample carry multiple ratings and especially for large deal volumes, issuers have but little choice as many investors and regulatory frameworks already require more than one credit rating. Whereas the beneficial effects for investors analyzed in this paper are a direct consequence from introducing additional rating agencies to a transaction, the implications for investors rather follow from market participants' adapted behavior under rating competition. In particular, issuers might be tempted to allocate more collateral to senior tranches at the expense of more junior tranches and the unrated equity class, By laying more weight on the senior tranche, issuers can lower their refinancing cost as credit spreads are typically lower for senior tranches with higher ratings. Backed by the credibility of multiple rating agencies (signaling), we expect issuers to be able to sell larger senior tranches to investors than in the absence of competition. The reduced bargaining power during single rating solicitation might further aggravate this effect as it increases risk of receiving a lower rating on the senior tranche. Accordingly, we formulate our third proposition as follows:

Proposition 3: $\quad$ The size of senior tranches in relation to total deal size is higher for multiplerated tranches compared to single-rated tranches.

\section{DATA}

Our analysis is based on a dataset combining credit rating information from three different sources. The joint data comprises the complete daily long-term credit rating migration of residential mortgage-backed securities rated by Standard \& Poor's, Moody’s Investors Service, and Fitch Ratings. Standard \& Poor's ratings are obtained through the S\&P Credit Ratings database on Wharton Research Data Services (WRDS). The global database uses the combined information of S\&P RatingsXpress and Compustat fundamental and market data, providing the credit rating migration of 205’670 RMBS tranches issued between 1977 and mid-2012. Moody's credit ratings are taken from the Structured Finance Default Risk Services database (SF-DRS) which covers the credit histories and material impairment of all Moody's-rated structured finance products issued since 1982. As of July 2012, the database includes historical changes in credit ratings of 94'216 RMBS tranches, segmented into 10'704 deals. Fitch credit 
ratings are provided by the Fitch Solutions Integrated Data Services (IDS) and include the global record of historical credit ratings since 1985 on both issuer- and tranche-level for the Fitch-rated structured finance universe offering sub-level debt classification of each rated tranche. The available record up to mid-2012 comprises 79’305 RMBS tranches from 1'515 different originators.

Besides daily rating migration, numerous deal- and tranche-level characteristics are available for each data set. All three records commonly feature a number of tranche-level security identifiers ${ }^{5}$ along with tranche name, original amount, asset type, domicile of assets, debt currency, issue launch date, legal maturity date, sub-industry classification, and information on credit enhancement or specialized financial structuring. Rating migration data include daily long- and short-term credit ratings and rating changes from the respective rating agencies, as well as watch list and rating outlook indications where applicable. S\&P and Fitch provide additional information on issuer- and entity-level for each tranche alongside with interest rates paid on debt obligations. Moody's record includes debt classification according to tranche seniority, impairment calculations for tranches in default, and several deal-level characteristics such as unique deal identification, deal name, and original sale amount.

\subsection{SAMPLE CONSTRUCTION}

In a first step, we eliminate tranches with missing data, which cannot be complemented by information provided by either one of our data sources. In particular, we exclude tranches without a unique security identifier code such as CUSIP, ISIN, or CINS. In order to rule out currency- and country-specific effects, we limit our analysis to the U.S. market by clearing the data of all transactions which are not denominated in USD, and whose majority of assets is not domiciled in the United States. We then match tranche records from S\&P, Moody's, and Fitch based on available security identifier codes. This enables us to identify single-rated and multiple-rated (i.e. double- and triple-rated) tranches. We refer to the terms single-, double-, and triple-rated with respect to coverage by S\&P, Moody's, and Fitch as these three rating agencies cumulatively account for about $91 \%$ of outstanding credit ratings of securitized assets in $2012^{6}$. However, we implicitly accept the possibility that some tranches might be rated by additional agencies which are not covered by our sample (either NRSRO or non-NRSRO certified).

\footnotetext{
${ }^{5}$ Identifiers include CUSIP (Committee on Uniform Security Identification Procedures), ISIN (International Securities Identification Number), CINS (CUSIP International Numbering System), GVKEY (Compustat ID), and CIK (Central Index Key), among others.

${ }^{6}$ Annual Report on Nationally Recognized Statistical Rating Organizations, U.S. Securities and Exchange Commission (SEC), December 2012.
} 
[Table 1 about here]

Concerning the matching of individual rating scales used by Moody's and Fitch, we refer to Table I, which outlines the mapping code of the individual alphanumerical rating classes on a numerical reference scale based on underlying one-year default probabilities (as published by S\&P, Moody's and Fitch). This approach is commonly used in finance literature to enable comparison of different rating scales (see e.g. Cantor \& Packer, 1997; Jewell \& Livingston, 1999). The matching on the lower end of the rating scale deserves some further explanation. Pursuant to rating definitions of S\&P (2013), Moody’s (2013), and Fitch (2013) the event of default is typically defined as either (i) a missed or delayed disbursement of a contractually-obligated interest or principal payment (excluding missed payments cured within a contractually allowed grace period), as defined in credit agreements and indentures; or (ii) a situation where the issuer has entered into bankruptcy filings, administration, receivership, liquidation or other formal winding-up procedure, or such a situation is believed to be inevitable based on the rating agencies' opinion. This definition corresponds to a credit rating of C on Moody's global long-term rating scale and a rating of D on S\&P and Fitch's international credit rating scale. However, a closer examination of near-to-default tranches rated by multiple agencies indicates that downgrades to $\mathrm{C}$ on behalf of Moody's (where $\mathrm{C}$ is the lowest rating category) rather corresponds to S\&P and Fitch downgrades to C (their second lowest rating category) than to their actual default rating $\mathrm{D}$. We thus account for differences in the practice of assigning ratings to indicate default by considering a tranche to be in default if it has been flagged by a rating below Ca on the Moody's rating scale or an equivalent CC on the S\&P and Fitch rating scales. From the individual numerical ratings we can calculate the change in notch difference for various time periods which enables us to identify the divergence in the credit quality assessment of multiple-rated tranches.

\subsection{Descriptive SAMPle StATISTICS}

A first overview on the scope of our sample is given in Figure 1. The chart reports the number of RMBS tranches for which an outstanding rating from S\&P, Moody's, and/or Fitch is available, segmented by calendar year. It illustrates the rapid growth of the RMBS market in the U.S., especially during the post-millennial period, before the outbreak of the subprime mortgage crisis led to a sudden collapse of the market in late 2007. Multiple ratings increasingly 
gained popularity although their growth has been stemmed in recent years. Whereas roughly one out of two tranches was rated by more than one rating agency in 1992, the share of single ratings has diminished to about $27 \%$ in the following decade and only constitutes a mere $24 \%$ of outstanding tranches in 2012.

[Figure 1 about here]

Monthly cross-sectional mean rating levels are shown in Figures 2.1 and 2.2. Not surprisingly, the picture is again dominated by the collapse of the RMBS market in late 2007. Average credit ratings, which have kept levels for fifteen years, lost substantial ground and fell over twelve rating notches after finally beginning to level off in 2010. Differences in agency specific rating records are generally small, yet S\&P seems to be slightly more optimistic about the credit quality of its mandated tranches across the sample period. Mean tranche ratings also differ with respect to the number of assigned ratings as shown in Figure 2.2. Single-rated tranches experienced a continuous deterioration of mean rating levels and appear to be relatively more conservative compared to multiple ratings, which remained particularly optimistic throughout the expansion of the structured finance market but have been more severely downgraded in the aftermath of the subprime crisis. While single ratings have lost on average about 5 notches between 2008 and 2010, mean multiple ratings deteriorated by roughly twice that much. In a recent study, Efing \& Hau (2013) explain this observation by demonstrating that credit ratings were biased towards issuer clients that provide the agencies with more rating business. While we will not draw premature conclusions about the difference in rating levels with respect to the single-multiple rating dichotomy in our sample, we will return to this observation during the interpretation of our results.

[Figures 2.1 and 2.2 about here]

A more nuanced picture of the final sample is given in Table 2 which reports selected tranche characteristics for a number of subsamples, notably for each rating agency and for single-, double, and triple-rated tranches. The combined record comprises a total of 154'608 tranches of which 42'668 (27.6\%) are single-rated, 91'118 (58.9\%) carry double ratings and 20’822 (13.5\%) have ratings assigned from all three rating agencies. As in the corporate bond market, S\&P maintains the largest share of outstanding credit ratings, providing credit statements for about $81.2 \%$ of tranches in the sample. Moody's is solicited for $57.5 \%$ of tranches 
while Fitch is still contracted with almost one out of two tranches. In general, tranche maturities do not appear to vary substantially across subsamples, although single-rated tranches tend to be of shorter maturity, compared to other subsamples. With an average of $\$ 72$ million, issuance volumes are particularly high for senior securities while subordinate tranches on average only amount to $\$ 13$ million. Additionally, issuance volumes seems to be positively correlated with the number of assigned ratings, suggesting that the size of a tranche might play a role in the issuer's decision, whether or not to solicit multiple ratings. This appears reasonable, as economies of scale allow allocating the costs for additional ratings to a wider asset base. Both maturity and volume are important factors for debt instruments and will be taken into account in the empirical analysis.

[Table 2 about here]

A distinct feature of multiple ratings is that they allow for a direct comparison between different rating agencies as they refer to the same debt instrument. We eliminate minor differences in publication dates (typically less than three months) by calculating the respective mean ratings over the first date on which the ratings of all involved rating agencies are publicly available. According to you records, additional ratings are neither solicited after issuance nor do we have relevant indication that they are withdrawn prior to maturity. An exception are tranches in or close to default (CC/Ca or below), where rating agencies might cease reporting at different points in time.

Among double ratings, rating differences between S\&P and Fitch are close to zero whereas Moody's ratings at issuance appear to be significantly more conservative. ${ }^{7}$ The ratings of triple-rated tranches seem to confirm this pattern. Moreover, the presence of a third rating agency coincides with an even stronger diverging opinion of Moody's, while the assessment of S\&P and Fitch remains roughly consistent. The relatively low market share of Moody's for single-rated tranches might further indicate that investors know about this relative conservativism and thus refrain from soliciting Moody's as a sole provider of credit opinion. Moody’s underrepresentation among single-rated tranches is therefore not surprising. We will address this notion in more detail in the empirical analysis. With respect to defaults, the statistics show a strong relationship between the number of assigned ratings and the rate of tranches which

\footnotetext{
${ }^{7}$ Recall that deviations in ratings issued by Moody's might at least partially be explained by different methodologies in determining the overall creditworthiness of an instrument. Moody's credit models are based on EL, reflecting both the likelihood of default and expected financial losses in the event of a default (loss given default) and may ceteris paribus be more favorable to large senior tranches than a PD approach, and less favorable towards smaller, more junior tranches.
} 
received a rating of $\mathrm{C}$ or below during the sample period. A possible explanation for this observation may ground on issuers' reliance on additional ratings particularly for low-quality assets in attempting to convince potential investors. This argument finds support in the fact that the proportion of multiple-rated tranches increased towards the run-up of the financial crisis, accompanied by decreasing quality of the assets being securitized.

\section{EMPIRICAL RESULTS}

To measure the effects of additional ratings on agency effort and the coherence of multiple ratings over time, we rely on fixed effects multiple linear regression analysis. Differences in classification accuracy of credit ratings are quantified using receiver operating characteristic. Both applications are widely accepted measures in financial literature and also commonly used in the context of multiple ratings (e.g. Jewell \& Livingston, 1999; Guettler \& Kraemer, 2008: Bongaerts et al., 2012). We proceed to address the hypotheses formulated in Section 2 by defining the identification strategy and methodology for each of the two research question, followed by a discussion of the empirical results.

\subsection{Do Multiple Ratings Foster MONitORing EFFORT?}

In order to determine the degree of rating and revision effort on behalf of rating agencies for single- and multiple-rated tranches, we use rating agencies' activity on tranche level as a proxy for agency effort. We quantify activity as the number of reviews of credit ratings (upgrade, downgrade, confirmed) and rating outlook (positive, negative, stable) for each tranche over a specific period of time. Frankly, periodic credit assessments do not always trigger a change in rating or outlook but may confirm the latest estimates by a more recent rating date. We therefore also include rating and outlook confirmations as they, alike actual rating changes, provide evidence for revision effort on behalf of rating agencies. Table 3 gives a first overview on rating activity and reports mean number of rating reviews along with standard deviation, minimum and maximum values for single and multiple ratings, rating agencies and different years. It is not surprising that the number of rating reviews by S\&P, Moody's, and Fitch about tripled from 2007 to 2008, when yearly rating activity typically assumed maximum values, shortly after the crisis began to reveal its entirety. In general, rating agencies' effort appears to 
be higher for multiple-rated tranches compared to single ratings as the corresponding test statistics are significant at the 0.01 confidence level, for the most part. Moreover, the effect appears more clearly during the crisis period, when S\&P and Moody's, but also Fitch reinforce their activities, particularly among multiple-rated tranches.

[Table 3 about here]

In the following we perform a multivariate regression analysis in order to assess the causal impact of multiple ratings on rating agencies' monitoring activity in the presence of covariates. We set up a linear regression equation and specify the covariates to be included in the model as follows:

$$
\begin{gathered}
\text { Activity }_{i, t}=\alpha_{\text {Issuer }}+\alpha_{Y e a r}+\alpha_{\text {Vintage }}+\beta_{1} \text { Mult }_{i}+\beta_{2} \text { Default }_{i} \\
+\beta_{3} \text { Rating }_{i, t}+\beta_{4} \text { TTM }_{i, T-t}+\beta_{5} \text { Size }_{i}+\beta_{6} \text { Coll }_{i}+\varepsilon_{i}
\end{gathered}
$$

The dependent variable Activity $_{i, t}$ is Rating Revision Activity and indicates the intensity of monitoring activity. It is defined as the total number of credit rating (and rating outlook) reviews performed on tranche $i$ in year $t$. We employ issuer-fixed effects to control for unobserved heterogeneity at the issuer level. As related research observes considerable differences in delinquency rates of residential mortgages with respect to loan vintage (e.g. Demyanyk \& Van Hemert, 2011) we also include dummy variables for each calendar year $\alpha_{\text {Year }}$ and tranche vintage year $\alpha_{\text {Vintage }}$ to control for time-varying heterogeneity in credit quality. The main explanatory variable Multiple Ratings (Mult ${ }_{i}$ ) is dichotomous and coded 0 if tranche $i$ is rated by more than one rating agency and 0 otherwise. We account for the notion that tranches on the path to default might be under close scrutiny of rating agencies and hence are likely to be subject to higher monitoring effort compared to tranches whose credit quality is still unabated. Ex Post Quality (Default ${ }_{i}$ ) controls for this effect by indicating whether a tranche eventually experiences default (1), or not (0). On a related note, rating activity tends to be higher among tranches at the lower end of the rating scale. We therefore also include the (mean) numerical Tranche Rating $\left(\right.$ Rating $\left._{i, t}\right)$ at the end of year $t$ to control for individual tranche credit quality. In addition, the frequency of rating and outlook revisions typically decreases as tranches approach final maturity ( $\mathrm{T}$ ) as ratings of tranches with shorter time to maturity are expected to be less prone to uncertainty. Thus, we let Time To Maturity $\left(T T M_{i, T-t}\right)$ denote remaining tranche lifetime in months defined as $T-t$. Size $_{i}$ refers to the natural logarithm of the tranche's original amount, 
denominated in USD and captures differences in revision effort related to tranche size. Finally, Collateral $\left(\mathrm{Coll}_{i}\right)$ is a zero-one variable and captures differences in the opaqueness of the underlying pool of assets by distinguishing assets backed by prime-rate borrowers (1) from those with underlying mortgages of inferior credit quality such as subprime or Alt-A papers ${ }^{8}(0)$. There is no formal definition of prime or subprime borrowers but according to industry standards, subprime borrowers were historically defined as having a FICO score ${ }^{9}$ below 640, although this has varied over time and circumstances (Lo, 2012). We do not include a variable related to tranche subordination since this effect is to a large extent already captured by the numerical tranche rating (Rating ${ }_{i, t}$ ) and inclusion of such does not significantly alter the goodness-of-fit statistics or coefficients of our explanatory variables. The error term is assumed to be normally distributed with $\varepsilon_{i} \sim N\left(0, \sigma^{2}\right)$. Yet, we relax the assumption of independent and identical distribution by applying cluster-robust standard errors, a clustered version of HuberWhite sandwich estimators to account for potential clusters on tranche level.

[Tables 4.1 to 4.3 about here]

The analysis is performed separately for each rating agency and the corresponding results are presented in Tables 4.1 to 4.3. The deal characteristics available for Moody’s ratings enable us in Table 4.2 to control for Deal Complexity, which captures the number of tranches comprising each deal, excluding the residual equity class retained by the issuer. In Column (1), we run a first regression on rating revision activity, considering only rating upgrades, downgrades, and confirmations. Column (2) presents the full sample results of monitoring activity including both rating and watch list revision activity. As the dependent variable captures the number of tranche reviews per year, we can interpret the coefficient as follows: for a one unit change in the predictor variable, the response variable is expected to change by the respective regression coefficient, given the other predictor variables are held constant. Thus, the estimated coefficient for Multiple Ratings predicts an increase in the number of rating reviews per year of about 3.1\% (S\&P) and 3.8\% (Moody’s) for tranches rated by more than one rating agency, compared to single ratings. The respective coefficient for Fitch is not statistically significant, but increases to $2.9 \%$ if rating outlook reviews are taken into account. As they result from slightly different model specifications, one should exert caution when comparing these numbers directly, but

\footnotetext{
${ }^{8}$ Alternative A-paper is a type of U.S. mortgage that is considered to be riskier than A-paper, or "prime", and less risky than "subprime".

${ }^{9}$ Originally created by the Fair Isaac Corporation, the FICO score is a type of credit score that uses mathematical models and takes into account various factors on payment history, current level of indebtedness, types of credit used, length of credit history, and new credit, to quantify the overall credit risk of an applicant. A person's FICO score will range between 300 and 850 . Scores above 650 indicate good credit history, while individuals with scores below 620 may often find it difficult to obtain financing at a favorable rate.
} 
they provide a useful indication on the overall magnitude of the effect. In Column 3 we run the regression over a subsample, including only tranches which eventually defaulted at some point in time. To facilitate comparability with Bongaerts et al. (2012) we further restrict our sample to multiple-rated tranches between 2002 and 2008 in Column 4. For this purpose we replace Mult $_{i}$ by Triple Rating (Triple $e_{i}$ ), which is dichotomous and coded 1 if a tranche carries ratings from all three rating agencies at time $t$ and 0 otherwise. In line with previous results, the subsample regressions display significantly higher relative rating activities for multiple-rated tranches and the effect appears to be substantially larger for tranches of ex post poor credit quality (11.1\% for S\&P, 8.7\% for Moody’s and 4.0\% for Fitch). Also for the subsample relating to Bongaerts et al. (2012) we observe an increase of rating activity by $4.6 \%$ for S\&P and $4.1 \%$ by Moody's when a third rating agency is solicited.

We perform several robustness checks in order to evaluate the sensitivity of our results towards different model specifications. First, we run a number of unreported regressions on the same model specifications, but with slightly altered subsample constraints, e.g. we allow the length of the observation period to vary and perform separate regressions for the pre-crisis and the crisis period. We also control for review outcomes (upgrade, downgrade, confirmed) by means of dummy variables but impact on regression coefficients and goodness-of-fit statistics is insignificant. In general, the analysis confirms the robustness of our results towards different model specifications. Coefficients for our main variables of interest are generally higher for the crisis period but overall in line with those presented in Table 4.1 to 4.3.

[Figures 3.1 to 3.3 about here]

From the baseline model in Column 1 (Tables 4.1 to 4.3) we calculate a series of margin post-estimations to get a more nuanced view on the effect of multiple ratings on monitoring effort. Margins are frequently used in Epidemiology and Biostatistics, but recently also in Economics ${ }^{10}$ as an informative means for summarizing how the value of a response variable is related to changes in a particular covariate or combination of such, holding the remaining variables at their means. The margins of linearly predicted number of rating reviews per annum (p.a.) for single- and multiple-rated tranches, along with 95\% confidence intervals, , are graphically illustrated in Tables 3.1 to 3.3. Several observations deserve to be highlighted in this

\footnotetext{
${ }^{10}$ For a detailed discussion of margins and marginal effects, in particular the distinction between average marginal effects (AME) and marginal effects at the mean (MEM) see e.g. Long (1997), Long \& Freese (2005), Bartus (2005), or Cameron \& Trivedi (2010).
} 
context. When comparing different levels of revision effort among single- and multiple-rated tranches in the subsamples of defaults and non-defaults, we can observe that revision activity of all rating agencies is significantly higher for multiple ratings across relevant calendar years. Confidence intervals for all pairwise comparisons do not overlap, and revision activity remains constant over time for S\&P and Moody's, but increases significantly on a year-to-year basis in the case of Fitch. Activity on behalf of all three rating agencies is also significantly higher for tranches with lower ex post credit quality (defaults). It is reasonable to conclude that tranches on the path to default are under close scrutiny by the rating agencies and hence have their ratings revised more frequently. The graphs presented in Figures 4.1 to 4.3 are similar, but display differences in revision activities across rating classes for selected years. In line with our expectations activity levels increase significantly as the market reaches its turning point in late 2007, but affecting both single- and multiple-rated tranches in the same way, the results remain consistent with our previous findings. Interestingly, Fitch displays a strong tendency to review tranches at the lower end of the rating scale more often while the frequency of Moody's and S\&P reviews is more balanced across the rating scale. Unreported post-estimations further reveal that activity levels depend strongly on tranche vintage, i.e. the year a tranche has been issued, with tranches issued just before the market's turning point in late 2007 receiving significantly more reviews in the following years. Between 2007 and 2011, tranches issued after 2005 received about three times more rating reviews compared to tranches issued before 2000 .

[Figures 4.1 to 4.3 about here]

With respect to Proposition 1, the above results allow us to reject the null hypothesis that rating effort does not vary with respect to the number of assigned ratings, and not reject the alternative hypothesis. The findings provide strong empirical evidence that rating agencies' level of rating and outlook revision activity is positively influenced by competition, i.e. the availability of peer ratings. We further observe an increase in revision activity during and after the subprime crisis. A possible interpretation of this result might be seen in the competitive pressure on rating agencies during tightening market conditions, when credit ratings are typically under closer scrutiny by regulators and investors. In such an environment, reputational concerns might be a crucial factor in rating agencies' effort to correctly determine an instrument's inherent credit risk. The threat of below-average performance, together with the fact that multiple-rated tranches allow for direct benchmarking with peers, creates a strong incentive for rating agencies to even further increase monitoring effort on this particular set of tranches. Our 
findings are in line with Efing \& Hau (2013) in a sense that relatively lower revision rates in the pre-crisis period support the view that issuer-friendly ratings, which presumably received little attention as long as the market thrived, were particularly prevalent in this period.

\subsection{Do Multiple Ratings InCREASE RATing ACCURACy?}

In the previous section, we focused on rating agencies' degree of effort in monitoring credit quality of single- and multiple-rated tranches and different market environments, and observed increased rating revision activity during and after the subprime mortgage crisis. As a consequence, we argue that higher levels of revision activity on behalf of rating agencies should ultimately be reflected in their overall rating performance. More precisely, one should be able to observe an improvement in rating agencies' ability to correctly discriminate between different levels of credit risk.

The classification accuracy of credit ratings can be described by using power curves, or so called receiver operating characteristic (ROC), which is a plot of the true positive rate (TPR), i.e. the proportion of actually defaulted tranches which are ex-ante correctly identified as such, versus the false positive rate (FPR), i.e. the proportion of non-defaults which are falsely identified as defaults. Equivalently, the ROC curve can be represented as the cumulative distribution function of the case marker observations (defaults), standardized with respect to the control distribution (non-defaults). We account for covariates that affect the distribution of the marker among controls. Following Janes \& Pepe $(2008,2009)$ we employ a covariate-adjusted measure of classification accuracy called the covariate-adjusted ROC curve, or the AROC. We then compare the summary measures of the AROC curves for single- and multiple-rated tranches to identify differences in the predictive power of credit ratings for the two subsamples. As the number of tranche defaults is particularly low in the pre-crisis period, we restrict our analysis to the crisis and post-crisis sample (2007 to 2011) where we have sufficient coverage of events to obtain statistically meaningful results.

As a first step, we fit a logistic regression model which is estimated using maximum likelihood, and specify how the covariates act on the distribution of the marker, i.e. the rating classification.

$$
\begin{gathered}
\text { Default }_{i, t}=\alpha_{\text {Vintage }}+\beta_{0}+\beta_{1} \text { Rating }_{i, t}+\beta_{2} \text { Effort }_{i, t}+\beta_{3} \text { Mult }_{i} \\
+\beta_{4} \text { TTM }_{i, T-t}+\beta_{5} \text { Size }_{i}+\beta_{6} \text { Coll }_{i}+\varepsilon_{i}
\end{gathered}
$$


The binary outcome variable Tranche Default (Default $t_{i, t}$ ) assumes 1 if a tranche $i$ has experienced a default event during the observation period $t$ and 0 otherwise. It can thus be interpreted as the default probability with respect to $t$. The marker, or classification variable Tranche Rating $\left(\right.$ Rating $\left._{i, t}\right)$ is the numerical long-term credit rating at the beginning of period $t$ and ranges from 1 (best rating) to 21 (worst rating/default). A number of covariates account for effects that potentially affect the distribution of the marker among controls. Monitoring Effort (Effort $t_{i, t}$ ) captures tranche differences in the number of rating reviews and is defined as the number of rating reviews that occur between inception at $t_{0}$ and the beginning of observation period at time t, divided by elapsed tranche lifetime (in months). In this respect, we create a dynamic measure of agencies' monitoring effort where the effect of rating reviews become less pronounced the further they occur from the observation point. Multiple Ratings (Mult $\left.{ }_{i}\right)$ is binary and indicates whether a tranche is rated by multiple rating agencies. The remaining covariates remain the same as in equation (1) and are described in the previous section. The distribution of the random error, $\varepsilon$, is estimated empirically by using the residuals from the linear model. The stratified measure of rating performance is then defined as

$$
A \operatorname{ROC}(f)=P\left(1-P V_{D Z} \leq f\right)
$$

where PV stands for percentile value, and $P V_{D Z}=F_{Z}\left(Y_{D Z}\right)$ represents the case observation with the covariate value $\mathrm{Z}\left(\mathrm{Y}_{\mathrm{DZ}}\right)$ standardized with respect to the control population with the same value of $\mathrm{Z}$. Accordingly, we estimate $\mathrm{F}_{\mathrm{Z}}$, the distribution of the marker in controls as a function of $\mathrm{Z}$. That is, for each case subject $i$ we calculate the PV:

$$
\widehat{P V}_{D Z_{i}}=\widehat{F}\left\{\left(Y-\widehat{\beta_{0}}-\widehat{\beta_{1}} M u l t_{i}-\widehat{\beta_{2}} \operatorname{Size}_{i}-\widehat{\beta_{3}} \operatorname{Coll}_{i}\right) / \hat{\sigma}\right\}
$$

where $\widehat{\beta_{0}}, \widehat{\beta_{1}}, \widehat{\beta_{2}}, \widehat{\beta_{3}}$, and $\hat{\sigma}$ represent estimates from the logit model. The cumulative distribution function of the estimated case percentile values is estimated empirically. We then calculate the area under the $A$ ROC curve, $A \mathrm{AUC}=\int_{0}^{1} A \mathrm{ROC}(f) d f$, which is given by

$$
\widehat{A \mathrm{AUC}}=\sum_{i=1}^{n_{D}} \widehat{P V}_{D Z_{i}} / n_{D}
$$


The AAUC estimate is the sample average of the case standardized marker values, where the sum is over the $n_{D}$ case observations and can be interpreted as the probability that, for a random case and control marker observation with the same covariate value, the case observation is higher than the control. Accordingly, the angle bisecting line, also called reference line, represents a random model where the marker provides no discriminatory power in ex ante distinguishing between case and control observation. We calculate the classification accuracy for each rating agency and different prediction periods, using credit ratings at the beginning of the respective period as classification variables. We let the binary outcome variable assume 1 if a tranche experiences a default in a given period and 0 otherwise. The variable thus captures a rating agency's capability to predict default up to the duration of the prediction period.

[Figures 5.1 to 5.3 about here]

Figures 5.1, 5.2 and 5.3 provide a graphical illustration of the estimated AROC curves for a one-year prediction period starting in the beginning of 2008. One can see that classification accuracy varies with respect to the number of assigned rating agencies. More precisely, the precision of rating schemes appears to increase with additional rating agencies joining the monitoring process. The corresponding AAUCs for each rating agency and different prediction periods are reported in Table 5. $\triangle$ AAUC captures the difference in classification accuracy for single- and multiple-rated tranches and results from subtracting the AAUC of single-rated tranches from the AAUC of multiple-rated tranches. A Wald statistic is obtained by dividing the observed difference by its standard error and compared to the standard normal distribution to obtain a p-value. Generally, the findings indicate significantly higher classification accuracy for multiple-rated tranches, particularly among S\&P and Fitch ratings where $\triangle A A U C$ displays strong statistical significance in the crisis and post-crisis period. The results in the Moody's panel are less conclusive. The predictive power of Moody's single ratings dominates those of multiples in 2009 and 2010, but is consistent with S\&P and Fitch in earlier periods. In addition, S\&P dominates its peers in terms of classification accuracy among multiple-rated tranches in the outbreak of the crisis in 2007 and 2008, but is outperformed by Fitch in the following years. Moody's ability to discriminate credit quality is typically below peer level for multiples, yet displays strong performance among single-rated tranches. ${ }^{11}$

\footnotetext{
${ }^{11}$ A possible explanation for the contradicting results for Moody's between 2008 and 2010 might be seen in the particularly low number of single-rated tranches of which only few defaulted, resulting in an increase of prediction accuracy. Due to the small sample on which the analysis is performed, we do not see these results to substantially influence our general interpretation.
} 
[Table 5 about here]

One might question whether the relatively higher discriminatory power of multiple ratings implies that the assessment is indeed more accurate for these tranches or whether the results are rather an outcome of the combined findings that (i) agencies are more conservative when competitors rate the same tranche and (ii) many tranches defaulted during the observation period. Given the nature of our data, disentangling these effects is not straightforward. But while there is little doubt about the large number of tranche defaults in our sample, Figure 2.2 provides some indication that rating agencies were not particularly conservative in assessing the credit quality of multiple-rated tranches. Rather, we observe a tendency towards even optimistic rating assessments under competition, a finding also confirmed by Efing \& Hau (2013). We do, however, not interpret this as evidence for rating inflation as we fail to observe signs of abnormal downward rating revisions after issuance which would be expected in such a case. We further control for rating agencies' relative conservativeness in our sample by performing separate subset analyses for each of them. Overall, the analysis of receiver operating characteristics suggests a predominantly positive impact of multiple ratings on rating agencies' ability to correctly classify tranches with respect to credit risk. Based on Proposition 2, we can thus reject the null hypothesis that classification accuracy does not vary with respect to number of assigned ratings, and not reject the alternative hypothesis for Fitch and S\&P. In addition, the results of our AROC analysis emphasize a steady decrease in the explanatory power of credit ratings towards the end of the sample period. Relating these findings to those of the previous section provides a strong argument that the observed increase in rating revision activity on behalf of rating agencies since the market turmoil in late 2007 ultimately might have manifested in higher classification accuracy of credit quality among multiple-rated tranches.

At first, one might see these results to contradict Bongaerts et al. (2012) who report no evidence of increased information production in case of multiple ratings on corporate bonds. In this regard, however, it shall be noted that the empirical setup in Bongaerts et al. (2012) differs from our analysis in several ways. A distinct feature of the corporate bond market is that bond issues are almost exclusively rated by more than one agency and the authors remove from their sample the remaining issues that do not have ratings from both Moody's and S\&P. Accordingly, their analysis of information production is restricted to cases where a third rating by Fitch is solicited. Rather than constituting an actual dissent, our findings can therefore be interpreted as complementary to Bongaerts et al. (2012). Taken together the results suggest that by introducing competition to the rating process, a second rating induces agencies to increase information 
production. The marginal benefit of an additional third rating on the other hand would be too small as to yield significant results in the empirical analysis. Such interpretation is, of course, tainted with the usual caveats that apply when findings are generalized across market segments and cannot be taken at face value. Albeit, the analysis serves to refine our understanding of the information contained in credit ratings and even points towards an optimal number of credit ratings in the context of investor's demand for information production. Moreover, the economic implications of our results are significant. Total defaults among single-rated tranches amounted to $26.4 \%$ in our sample. In dollar terms, this corresponds to roughly 110 USDbn estimated potential losses to investors in this segment. More disciplined behavior on behalf of rating agencies among single-rated tranches could have contributed to a more timely and accurate prediction of these losses up to several years ahead.

\section{ISSUERS’ INCENTIVES FOR MULTIPLE RATINGS}

As outlined in Section 2, related literature brought forth a number of incentives which serve as potential motivation for issuers to solicit multiple ratings. Most notable in this context are incentives related to overcome specific regulatory certification hurdles, and the rating shopping hypothesis (e.g. Jewel \& Livingston, 1999). In addition, we present evidence of another incentive related to the tranching process. Empirical documentation around multiple ratings in connection with regulatory certification is typically weak (e.g. Cantor \& Packer, 1995/1997). However, Bongaerts et al. (2012) conclude that marginal, additional credit ratings are more likely to occur because of, and seem to matter primarily for, regulatory purposes. As a result of the disruptive events during the recent financial crisis, the regulatory framework around structured finance assets has been, and still is, subject to a major overhaul. While entering the depths of the regulatory guidelines issued by relevant supervisory authorities is beyond the scope of this paper, reflections around transaction structuring and the concept of rating shopping deserve some further attention.

\subsection{Shift of Collateral Towards Senior Rating Classes}

Since the abandonment of the subscription approach by Moody’s, Fitch, and finally S\&P in the early 1970s, the rating market for securitization transactions is traditionally characterized by solicitation, meaning that the issuer selects and pays involved rating agencies for evaluating 
a security's credit quality. Such an issuer-pays business model can be source of a range of conflicts of interests for issuers. As already discussed in Section 2, the additional credibility that accompanies additional credit ratings along with increased bargaining power when soliciting multiple bids provide an incentive for issuers to shift potentially inferior collateral from more junior towards senior tranches during the structuring process. To test this hypothesis we set up the following linear regression model to analyze the impact of multiple ratings on tranche size:

$$
\text { Size }_{i}=\alpha_{\text {Issuer }}+\alpha_{\text {Year }}+\alpha_{\text {Vintage }}+\beta_{1} \text { Mult }_{i}+\beta_{2} \text { DSize }+\beta_{6} \text { Coll }_{i}+\varepsilon_{i}
$$

The dependent variable Size ${ }_{i}$ refers to the natural logarithm of the tranche's original amount, denominated in USD. We control for Deal Size (DSize) denoted as the natural logarithm of the deal's original amount in USD. For a deal structured into $\mathrm{n}$ tranches, DSize is equal to the sum of all individual tranche sizes, excluding the unrated equity class retained by the issuer:

$$
\text { DSize }=\sum_{i=1}^{n} \text { Size }_{i}
$$

All other controls remain the same as in equation (1). We run separate regressions for each rating class, but report them here in groups of three for reasons of clarity. The corresponding results are shown in Table 6. As the dependent variable is log transformed, the exponentiated value of the coefficient for Multiple Ratings in the log scale is the difference in the expected geometric means of the log of tranche size between single-rated and multiple-rated tranches. In the original scale of the variable Tranche Size, it is the ratio of the geometric mean of tranche size for multiple ratings over the geometric mean for single ratings. Accordingly, the effect for tranches rated no lower than Aa2 equals $e^{0.5206}=1.683$. In terms of percentage change, we can say that we expect to see about 68.3\% increase in the geometric mean of tranche size for multiple-rated tranches in these rating classes. For the second group of ratings at issuance the effect already reduces to $43.7 \%$ and is insignificant for the middle range of the rating scale. This shift of assets towards senior rating classes happens not only at the expense of the lowest rating categories, among which tranches with multiples ratings are about $2.60 \%$ smaller, but also of the unrated equity class.

[Table 6 about here] 
With respect to Proposition 3 the results allow us to reject the null hypothesis that the size of senior tranches is not higher for multiple-rated tranches compared to single-rated tranches when controlled for the size of the deal. Issuers benefit from multiple ratings in the form of lower refinancing cost. This is possible as investors appear to be more willing to invest in relatively larger senior tranches when they are backed by more than one credit rating. We consider the economic relevance of this effect to be quite substantial. By allocating additional, and by definition, inferior collateral to senior tranches, issuers impede the overall quality of these tranches. The senior tranche, being the safest asset in the deal, usually receives AAA/Aaa accreditation. The impairment is therefore unlikely to result in a lower credit rating, materializing negatively from an investor's point of view.

\subsection{RATING SHOPPING}

Another conflict of interest that might arise from the issuer-pays model is rating shopping (e.g. Jewell \& Livingston, 1999). Under the rating shopping hypothesis, issuers 'shop' for additional ratings in the hope of improving their rating or meeting regulatory certification standards. According to this theory, rating shopping can emerge when rating agencies do not perfectly agree or there is increased uncertainty about an instrument's credit quality. In this case, issuers, who have additional, private information about the tranches' credit quality, can seek to maximize their average rating by soliciting multiple bids. In exchange for a small break-up fee, issuers can keep an already solicited credit rating confidential as they own the publication rights for solicited ratings (Mählmann, 2008). Issuers have, by definition, a very strong incentive to get c. p. the best possible rating for the debt instruments they intend to sell because investors' return expectations are a function of the underlying credit quality. The higher the credit risk, the higher the interest rates demanded by investors. We further assume that investors assess the yield they demand on the basis of the average credit ratings in case of more than one credit rating. Accordingly, issuers have an interest in additional (and better) ratings, because it will lead to lower refinancing costs. On the other hand, investment policies, particularly of large institutional investors, may constrain rating shopping as they quite often demand more than one rating. In such cases, the issuer is required to publish a second rating in addition to the (most favorable) rating which would reflect his rational choice. In this section, we do not focus on actual refinancing costs but aim to shed light on issuers' incentives for rating shopping by focusing on the postissuance period of multiple-rated tranches. Multiple ratings provide a unique opportunity to 
directly compare credit assessment and subsequent monitoring of different rating agencies on the same asset.

In general, we see several arguments which motivate issuers to engage in rating shopping. On the one hand, split ratings at the time of issuance might incentivize issuers to solicit rating agencies which provide a more optimistic credit assessment than their competitors. This welldocumented effect has been the primary focus of recent literature related to the rating shopping phenomenon. In addition, we argue that rating shopping is also driven by issuer's expectations about relative future rating migration. We therefore extend the existing theory to a more dynamic environment taking into account the monitoring period after issuance.

Two potential scenarios may exist: (i) Rating agencies are indeed trading in favorable ratings at issuance for being solicited by the issuer (e.g. AAA instead of AA). Throughout the post-issuance period, rating agencies are expected to adjust their credit assessment to reflect the fair credit quality. The average mean rating would come down and in case of split ratings, we would also expect that the rating gap would become smaller and even vanish completely overtime. The cost of rating shopping is borne by the investors in the form of lower yields at issuance. (ii) Structural differences between rating processes exist that cause the rating gap to remain stable or even increase over a tranche's lifetime, meaning that the full (dis)advantage of rating shopping becomes evident over time. These structural differences can, for example, result from different estimation processes for recovery rates or applied methodology, as discussed in Section 2. In this case, investors have to bear the (increasing) cost of rating shopping throughout the whole maturity structure. As existing literature only focuses on rating shopping at tranche issuance (e.g. Skreta \& Veldkamp, 2009), it may actually underestimate the real costs of rating shopping that is borne by investors. We argue that, if systematic divergence of credit ratings are persistent in the long run as described in scenario (ii), the related literature actually underestimates issuer's incentives for rating shopping. In this case, such long-run considerations might even outweigh marginal differences in ratings at the time of issuance. In order to investigate systematic differences in credit ratings of multiple-rated tranches, we rearrange our sample according to a tranche-term perspective and define a discrete variable Tranche Age $\left(\right.$ Age $\left._{i, t}\right)$ indicating the current age of tranche $i$, i.e. the time in months between issue launch date and time of observation in month $t$. We then assemble the individual end-of-month observations according to a term perspective, where 0 represents the month of issuance.

[Figures 6.1 to 6.3 about here] 
Figures 6.1, 6.2, and 6.3 show the resulting rating term curves for multiple-rated tranches and pairwise combinations of rating agencies. Two observations deserve particular attention: First, numerical notch differences of multiple ratings appear to increase with respect to tranche age for all pairings, but particularly for S\&P/Moody's-rated tranches, while Fitch ratings tend to re-converge with Moody's after about two years. Second, consistent with the analysis of multiple ratings at issuance, a direct comparison of the graphs confirm Moody's relative conservativeness in the long run and might serve as a potential explanation why only few issuers solicit Moody's on a standalone basis. ${ }^{12}$ The systematic and time-persistent differences in rating levels provide a strong motivation for issuer clients to engage in rating shopping activities. Issuers might be tempted to exploit the differences in credit assessments in order to maximize the ratings of their securities. The distribution of single solicitations in Table 2 supports this view. For example, Moody's share of single-rated tranches of 5.6\% is much lower compared to single ratings in the S\&P (21.9\%) and Fitch (14.1\%) portfolios, despite Moody's overall market share being substantially higher than Fitch's. These data suggest that issuers, to some extent, know about the relative differences in ratings from S\&P and Fitch versus Moody's and use this information in the solicitation process. They tend to refrain from soliciting single ratings from the most conservative rating agency. Instead, they more frequently publish conservative ratings in combination with credit opinions from a more optimistic rating agency in order to lessen the adverse effects of inferior ratings.

In a next step, we confirm the relationship between rating divergence and tranche age in a multivariate setup. The dependent variable $\operatorname{Gap}_{i, t}$ denotes the Rating Gap, i.e. the numerical notch difference between two ratings of tranche $i$ in month $t$. We take account of temporal variation in the dependent variable related to the year of tranche issuance include time-fixed effects. We include an additional binary variable Triple Rating (Triple ${ }_{i}$ ) to distinguish between double- (0) and triple-rated tranches (1). We do not directly consider numerical credit ratings, as given the setup, each observation involves multiple ratings. But we account for the overall level of seniority by means of a zero-one variable Tranche Seniority $\left(\operatorname{Sen}_{i}\right)$, coded one for senior tranches, and zero for AAA-subordination. Further, we employ the same control variables for remaining time to maturity, tranche size, and collateral quality as in previous models. Thus, we obtain the following regression equation:

\footnotetext{
${ }^{12}$ As Moody's ratings appear to be most conservative, it would be interesting to see whether they are also more accurate compared to S\&P and Fitch. We think that this topic merits further analysts and address the differences in relative performance of rating agencies in a separate paper.
} 


$$
\begin{gathered}
\operatorname{Gap}_{i, t}=\alpha_{\text {Vintage }}+\beta_{1} \text { Age }_{i, t}+\beta_{2} \text { Triple }_{i}+\beta_{3} \text { Sen }_{i}+\beta_{4} \text { TTM }_{i} \\
+\beta_{5} \text { Size }_{i}+\beta_{6} \operatorname{Coll}_{i}+\varepsilon_{i}
\end{gathered}
$$

As we model a count variable, i.e. a variable that take more than two values and all of the values are integers, we employ a fixed effects negative binominal regression model which is estimated using maximum likelihood. We also run the regression in a multiple linear setup. Both models yield very similar results and particularly the variation with respect to our main variables of interest is negligible. We therefore adhere to the negative binominal model, as the standard for modelling count variables as it is more robust with respect to assumptions on the underlying distribution of the dependent variable. Cluster-robust standard errors account for potential clusters on tranche level.

Table 7 reports the results for pairwise combinations of multiple-rated tranches for the total period (1985-2012) and a reduced pre-crisis sample (1985-2006). Coefficients for tranche age are positive and highly significant for all model estimations, and appear to be higher for the total period. Although the effect is also clearly present in the pre-crisis sample, the most recent years seem to have strongly reinforced the divergence of multiple credit ratings. Interestingly, the variable for triple ratings is also highly significant, suggesting that the rating gap for any agency pairings is larger when a third rating agency is involved. A third rating thus appears to increase the level of uncertainty among the first and second agency about a tranche's credit quality, rather than decrease it. Moreover, predictor variables for subordination are negative and significant, indicating that rating gaps are larger for mezzanine and subordinate tranches. This might be due to the fact that uncertainty in assessing credit quality is generally higher among junior tranches of a deal, as they are the first to absorb the losses should borrowers default on their repayment. This increased level of uncertainty might additionally aggravate the diverging tendency between different ratings of multiple-rated tranches.

\section{[Table 7 about here]}

As a further robustness check, we calculate a series of marginal effects based on equation (6) to investigate how changes in the response variable are related to changes in a particular covariate. Two measures can be used in this context, the average marginal effect (AME) and the marginal effect at the mean (MEM). The former refers to the computation of each observation's marginal effect with respect to an explanatory factor, averaged over the estimation sample. In contrast, MEM measures change in the response while holding all other variables at their 
means. Current practice tends to favor the use of AME for several reasons. ${ }^{13}$ In accordance with these concerns, we follow the established methodology of computing average marginal effects and synonymously refer to AME when we discuss marginal effects in the remainder of this paper.

The computation of marginal effects is different for discrete (i.e. categorical) and continuous variables and, in the context of linear statistical models, also varies in terms of interpretation. With binary independent variables, marginal effects measure discrete change, i.e. the average change in the expected value of the response variable, in our case $G_{i, t}$, if one independent variable changes from 0 to 1 , holding all other variables constant. That is, for a categorical variable $Z_{k}$ the AME is

$$
A M E_{k}=\frac{1}{n} \sum_{x=1}^{n}\left[F\left(\beta Z^{x} \mid Z_{k}^{x}=1\right)-F\left(\beta Z^{x} \mid Z_{k}^{x}=0\right)\right]
$$

where $\beta Z^{x}$ denotes the value of the linear combination of parameters and variables for the $x$ th observation and $F(\cdot)$ is the cumulative distribution function that maps the values of $\beta Z^{x}$ to the $[0,1]$ interval. On the other hand, marginal effects for continuous variables measure the instantaneous rate of change and provide an approximation to the amount of change in $G_{i, t}$ that will be produced by a 1-unit change in $Z_{k} \cdot{ }^{14}$ In this case, researchers typically estimate the effect of an infinitely small change. Let $f(\cdot)$ be the derivative of $F(\cdot)$ with respect to $\beta Z$. The AME of the continuous variable $Z_{k}$ is then given by

$$
A M E_{k}=\beta_{k} \frac{1}{n} \sum_{x=1}^{n} f\left(\beta Z^{x}\right)
$$

The AMEs for selected values of tranche age in combination with binary variables for triple ratings and seniority for the total sample are depicted in Table 8 . The instantaneous rate of change in the rating gap shows a positive, nonlinear correlation with tranche age. In other

\footnotetext{
${ }^{13}$ For example, MEM are not good approximations of AME, computed as means of marginal effects evaluated at each observations, if some of the parameter estimates are large. But issues also arise in terms of interpretability. Notably, it is generally viewed to be problematic to evaluate marginal effects at means of dummy variables since means of dummies refer to nonexistent observations (e.g. Bartus, 2005).

${ }^{14}$ A potential issue may arise with continuous variables in the sense that there is no guarantee that a bigger increase in $Z_{k}$ would produce an increase in the response variable equal to the increase in $Z_{k}$ times the instantaneous rate of change. This is because the relationship between $Z_{k}$ and the response variable is nonlinear. Yet, when $Z_{k}$ is measured in small units, the effect of an increase in $Z_{k}$ by unity may match up well with the marginal effect for $Z_{k}$. However, in response to the fact that the presentation of a single marginal effect for each covariate may or may not be informative in assessing the effect of changes on the response variable, Long (1997) and others suggest to examine adjusted predictions across a range of discrete values for one or more covariates (continuous or discrete). That is, we can look at the effects of discrete changes in categorical and continuous variables simultaneously, in order to get a more nuanced picture of the impact of covariates on the response variable.
} 
words, not only do rating gaps become larger, but the rate of change also increases with tranche age. For example, the expected monthly change in the rating gap for S\&P/Fitch-rated tranches increases from 0.016 notches at a tranche age of 0.5 years to 0.235 notches three years after issuance. Change rates for S\&P/Moody's and Moody's/Fitch combinations increase slightly more moderately during the same period from 0.025 to 0.196 notches, and from 0.019 to 0.139 notches, respectively. The post estimation of marginal effects also confirms the effects of a third rating, and subordination on the rating gap. We observe systematically higher AMEs for the subsamples of triple-rated tranches for combinations including a rating from Fitch, but also the difference in rating gaps between S\&P and Moody's is moderately significant with respect to triple ratings. For mezzanine and subordinate tranches, the sensitivities of age on the rating gap are even higher. We further compute AMEs for selected vintages. Age effects on the predicted rating gap three years after issuance are on average about three to four times larger for tranches which have been issued after 2002. In fact, tranches of the 2007 vintage series were equally prone to age-depending changes in rating gaps as the average subordinate tranche in the sample. Overall, the marginal effects on predicted rating gap are less pronounced when computed over the pre-crisis subsample. Rating gaps tend to increase linearly with tranche age but the effects lack statistical significance. However, there is a significant difference in rating gaps with respect to triple ratings, subordination, and, to a limited extent, also tranche vintage.

[Table 8 about here]

In summary, the time series analysis of multiple ratings provides suggestive empirical evidence that structural differences in rating methodologies are reflected by diverging credit ratings of mortgage-backed assets, which in turn constitute a strong incentive for issuers to engage in rating shopping. In addition, the findings suggest that the effects of certain tranche characteristics on the rating gap, although veritably existing before the subprime mortgage crisis, have been amplified to a large extent by it.

\section{CONCLUSION}

This study explores potential reasons for the existence of multiple credit ratings in the securitization market. Based on the complete rating migration for U.S. RMBS transactions, and thus avoiding a potential selection bias, we analyze potential incentives to obtain multiple rat- 
ings, induced by credit agencies' monitoring behavior following the issuance of securitized assets. We supplement existing research on multiple ratings by focusing on incremental information produced by additional credit ratings during the post-issuance period. Our results hold good news for investors: In a competitive situation of multiple ratings outstanding, we observe that the rating effort of each individual rating agency is increasing, leading to more information being produced. In a subsequent step, we document that multiple ratings not only lead to more but also to better information: Default prediction accuracy increases with the number of outstanding ratings. Thus, we empirically support the information production hypothesis and extend it to a dynamic framework. The economic implication of these results is that more disciplined behavior on behalf of rating agencies among single-rated tranches could have contributed to a more timely and accurate prediction of about 110 USDbn of potential losses to investors.

Issuers on the other hand benefit from more favorable transaction structures and incentives to engage in rating shopping activities, both eventually lowering their refinancing cost. Manifested by an increasing rating gap, we further find that disagreement among rating agencies widens over a tranche's lifetime. We thus conclude that rating shopping is not only motivated by split ratings at issuance, but also by issuers' expectations about relative future rating migration, a notion not considered in the prevalent literature on multiple ratings. However, we do not find empirical evidence that rating agencies are revising potentially inflated ratings in the monitoring period. Consistent with the analysis of ratings at issuance, direct comparisons of multiple ratings throughout the post-issuance period suggest a more conservative credit assessment on behalf of Moody's, providing a potential explanation why its market share among single-rated tranches is only $11.6 \%$, far lower than the agency's total market share of $32.8 \%{ }^{15}$

Our findings reinforce the calls among policy makers and regulators around the potential benefits of increasing competition between ratings providers as a tool for improving ratings quality. The transparent and concentrated market structure as well as the absence alternative sources of information for investors mark the U.S. RMBS market as an ideal environment to analyze the importance of multiple credit ratings. Yet, we argue that application of our results is not limited to RMBS, but also relates to structured finance in general as well as other markets. However, the effect of competition among rating agencies might be smaller due to less stringent reliance on ratings in other market segments as competition of information providers is more intense.

${ }^{15}$ Annual Report on Nationally Recognized Statistical Rating Organizations, U.S. Securities and Exchange Commission (SEC), December 2012, p. 6. 


\section{REFERENCES}

Bannier, C. \& Tyrell, M. (2006). Modelling the Role of Credit Rating Agencies - Do They Spark Off a Virtuous Cycle? Finance and Accounting Working Paper No 160, GoetheUniversität Frankfurt/M.

Bartus, T. (2005). Estimation of marginal effects using magreff. The Stata Journal, 5 (3), pp. 309-329.

Bolton, P., Freixas, X. \& Shapiro, J. (2012). The Credit Ratings Game. The Journal of Finance, 67 (1), pp. 85-111.

Bongaerts, D., Cremers, K.J.M. \& Goetzmann, W.N. (2012). Tiebreaker: Certification and Multiple Credit Ratings. The Journal of Finance, 67 (1), pp. 113-152.

Cameron, A.C. \& Trivedi, P.K. (2010). Microeconometrics using Stata, Revised Edition. StataCorp LP.

Cantor, R. \& Packer, F. (1995). The Credit Rating Industry. Journal of Fixed Income, 5 (3), pp. 10-34.

Cantor, R. \& Packer, F. (1997). Differences of opinion and selection bias in the credit rating industry. Journal of Banking \& Finance, 26 (10), pp. 1395-1417.

Diamond, D.W. (1984). Financial intermediation and delegated monitoring. Review of Economic Studies, 51 (3), pp. 393-414.

Demyanyk, Y. \& Van Hemert, O. (2011). Understanding the Subprime Mortgage Crisis. Review of Financial Studies, 24 (6), pp. 1848-1880.

Efing, M. \& Hau, H. (2013). Structured Debt Ratings: Evidence on Conflicts of Interest. Journal of Financial Economics, forthcoming.

Fender, I. \& Kiff, J. (2005). CDO Rating Methodology: Some Thoughts on Model Risk and its Implications. Journal of Credit Risk, 1 (3), pp. 37-58.

Guettler, A. \& Kraemer, W. (2008). On Comparing the Accuracy of Default Predictions in the Rating Industry. Empirical Economics, 34 (2), pp. 343-356.

Hsueh, L.P. \& Kidwell, D.S. (1988). Bond Ratings: Are Two Better Than One? Financial Management, 17 (1), pp. 46-53.

Janes, H., \& M.S. Pepe (2008). Adjusting for covariates in studies of diagnostic, screening, or prognostic markers: An old concept in a new setting. American Journal of Epidemiology, 168 (1), pp. 89-97.

Janes, H. \& Pepe, M.S. (2009). Adjusting for covariate effects on classification accuracy using the covariate-adjusted ROC curve. Biometrika, 96 (2), pp. 371-382. 
Jewell, J. \& Livingston, M. (1999). A Comparison of Bond Ratings from Moody's S\&P and Fitch IBCA. Financial Markets, Institutions \& Instruments, 8 (4), pp 1-45.

Lo, A.W. (2012). Reading about the Financial Crisis: A Twenty-One-Book-Review. Journal of Economic Literature, 50 (1), pp. 151-178.

Long, J.S. (1997). Regression Models for Categorical and Limited Dependent Variables. In: Advanced Quantitative Techniques in the Social Sciences Number 7. Sage Publications.

Long, J.S. \& Freese, J. (2005). Regression Models for Categorical Outcomes using Stata, Second Edition. College Station, TX: Stata Press.

Lugo, S., Croce, A. \& Faff, R. (2014). Herding Behavior and Rating Convergence among Credit Rating Agencies: Evidence from the Subprime Crisis. Review of Finance Advanced Access, pp. 1-29.

Mählmann, T. (2008). Rating agencies and the role of rating publication rights. Journal of Banking and Finance, 32 (11), pp. 2414-2422.

Moody's Investors Service (2007). Comment Letter on Proposed Rules regarding Oversight of Credit Rating Agencies registered as Nationally Recognized Statistical Rating Organizations. U.S. Securities and Exchange Commission. www. sec.com.

Morkoetter, S. \& Westerfeld, S. (2009). Do Multiple CDO Ratings Impact Credit Spreads? The Journal of Fixed Income, 19 (1), pp. 55-72.

Peretyatkin, V. \& Perraudin, W. (2002): EL and DP Approaches to Rating CDOs and the Scope for 'Ratings Shopping'. In: Ong, M. K. (ed), Credit Ratings - Methodologies, Rationale and Default Risk, London: Risk Books.

Sangiorgi, F., Sokobin, J. \& Spatt, C. (2009). Credit-Rating Shopping, Selection and the Equilibrium Structure of Ratings. NBER Working Paper No. 14712.

SIFMA (2015). Issuance in the U.S. Bond Market. http://www.sifma.org/research/statistics.aspx. Derived 25.01.2016.

Skreta, V. \& Veldkamp, L. (2009). Ratings shopping and asset complexity: A theory of ratings inflation. Journal of Monetary Economics, 56 (5), pp 678-695. 
Table 1: Numerical Rating Mapping Code

This table shows the numerical mapping code which is applied to the individual global long-term credit rating scales based on underlying one-year default probabilities reported by S\&P, Moody's and Fitch.

\begin{tabular}{cccc}
\hline \hline Rating Code & $\begin{array}{c}\text { S\&P Long-term Rat- } \\
\text { ing Class }\end{array}$ & $\begin{array}{c}\text { Moody's Long-term Rat- } \\
\text { ing Class }\end{array}$ & $\begin{array}{c}\text { Fitch Long-term Rat- } \\
\text { ing Class }\end{array}$ \\
\hline 1 & AAA & Aaa & AAA \\
2 & AA+ & Aa1 & AA+ \\
3 & AA & Aa2 & AA \\
4 & AA- & Aa3 & AA- \\
5 & A+ & A1 & A+ \\
6 & A & A2 & A \\
7 & A- & A3 & A- \\
8 & BBB + & Baa1 & BBB + \\
9 & BBB & Baa2 & BBB \\
10 & BBB- & Baa3 & BBB- \\
11 & BB+ & Ba1 & BB+ \\
12 & BB & Ba2 & BB \\
13 & BB- & Ba3 & BB- \\
14 & B + & B1 & B+ \\
15 & B & B2 & B \\
16 & B- & B3 & B- \\
17 & CCC+ & Caa1 & CCC+ \\
18 & CCC & Caa2 & CCC \\
19 & CCC- & Caa3 & CCC- \\
20 & CC & Ca & CC \\
21 & C & C & C \\
21 & D & & D / DD / DDD \\
\hline
\end{tabular}


Table 2: Summary Statistics

This table shows summary statistics and selected tranche characteristics of all available USD-denominated RMBS tranches issued between January 1985 and July 2012 . The sample only includes securities whose underlying assets are predominantly domiciled in the United States. S\&P ratings are obtained from the S\&P Credit Ratings database in WRDS, Moody's ratings are from the Structured Finance Default Risk Services database (SF-DRS), and Fitch ratings are provided by Fitch Solutions Integrated Data Services (IDS). Test statistics of equality of mean rating codes at issuance are obtained by a two-sample t-test.

\begin{tabular}{|c|c|c|c|c|c|c|c|c|c|}
\hline \multirow{2}{*}{ Subsample } & \multirow{2}{*}{$\begin{array}{c}\text { \# of rated } \\
\text { Tranches }\end{array}$} & \multirow{2}{*}{$\begin{array}{r}\text { in \% of Total } \\
\text { Sample }\end{array}$} & \multirow{2}{*}{$\begin{array}{r}\text { Mean Maturity } \\
\text { (in years) }\end{array}$} & \multirow{2}{*}{$\begin{array}{l}\text { Mean Volume } \\
\text { (in USDm) }\end{array}$} & \multicolumn{3}{|c|}{ Mean Rating Code at Issuance } & \multirow{2}{*}{$\begin{array}{l}\text { \# of Tranches } \\
\text { in Default }\end{array}$} & \multirow{2}{*}{$\begin{array}{r}\text { in \% of Sub- } \\
\text { sample }\end{array}$} \\
\hline & & & & & S\&P & Moody's & Fitch & & \\
\hline Total Sample & 154'608 & $100.00 \%$ & 28.83 & 48.60 & 3.15 & 2.98 & 3.04 & $49^{\prime} 022$ & $31.71 \%$ \\
\hline \multicolumn{10}{|l|}{ Rating Agency } \\
\hline $\mathrm{S} \& \mathrm{P}$ & $125 ' 498$ & $81.17 \%$ & 28.96 & 52.10 & 3.15 & - & - & $41 ' 949$ & $33.43 \%$ \\
\hline Moody's & 88'955 & $57.54 \%$ & 29.05 & 59.20 & - & 2.98 & - & 31'855 & $35.81 \%$ \\
\hline Fitch & 72'917 & $47.16 \%$ & 28.97 & 46.70 & - & - & 3.04 & $22 ' 836$ & $31.32 \%$ \\
\hline \multicolumn{10}{|l|}{ Subordination } \\
\hline Senior (AAA) & 97'599 & $63.13 \%$ & 28.34 & 72.10 & 1.00 & 1.05 & 1.01 & $14 ' 942$ & $15.31 \%$ \\
\hline Subordinate & $57 ' 009$ & $36.87 \%$ & 29.68 & 13.30 & 7.06 & 6.56 & 7.36 & $34 ' 080$ & $59.78 \%$ \\
\hline \multicolumn{10}{|l|}{ Collateral } \\
\hline First Mortgage & $85^{\prime} 457$ & $55.27 \%$ & 29.08 & 41.40 & 2.38 & 2.32 & 2.42 & 22'991 & $26.90 \%$ \\
\hline Subprime Mortgage & $35 ' 246$ & $22.80 \%$ & 28.80 & 67.20 & 3.99 & 4.17 & 4.19 & $15^{\prime} 469$ & $43.89 \%$ \\
\hline Other & 33'905 & $21.93 \%$ & 28.23 & 45.20 & 3.93 & 2.70 & 3.56 & $10 ' 562$ & $31.15 \%$ \\
\hline \multicolumn{10}{|l|}{ Single Rating } \\
\hline Total & $42 ' 668$ & $27.60 \%$ & 28.08 & 27.70 & - & - & - & $11 ' 281$ & $26.44 \%$ \\
\hline S\&P & $27^{\prime} 439$ & $17.75 \%$ & 27.89 & 27.70 & 4.98 & - & - & 7'171 & $26.13 \%$ \\
\hline Moody's & 4'957 & $3.21 \%$ & 27.85 & 39.80 & - & 3.68 & - & 580 & $11.70 \%$ \\
\hline Fitch & 10'272 & $6.64 \%$ & 28.87 & 20.90 & - & - & 7.14 & 3'530 & $34.37 \%$ \\
\hline \multicolumn{10}{|l|}{ Double Rating } \\
\hline Total & 91'118 & $58.93 \%$ & 29.01 & 52.70 & 2.45 & 2.73 & 1.87 & $27 ' 864$ & $30.58 \%$ \\
\hline S\&P / Moody's ${ }^{a}$ & $49 ' 295$ & $31.88 \%$ & 29.26 & 62.20 & 2.79 & 2.92 & - & $18 ' 435$ & $37.40 \%$ \\
\hline S\&P / Fitch ${ }^{\mathrm{b}}$ & 27'942 & $18.07 \%$ & 29.05 & 41.60 & 1.83 & - & 1.84 & $6^{\prime} 466$ & $23.14 \%$ \\
\hline Moody's / Fitch ${ }^{\mathrm{c}}$ & $13 ' 881$ & $8.98 \%$ & 28.04 & 39.00 & - & 2.05 & 1.92 & 2'963 & $21.35 \%$ \\
\hline \multicolumn{10}{|l|}{ Triple Rating } \\
\hline S\&P / Moody's / Fitch ${ }^{\mathrm{d}}$ & $20 ' 822$ & $13.47 \%$ & 29.52 & 69.50 & 3.36 & 3.57 & 3.35 & 9'877 & $47.44 \%$ \\
\hline
\end{tabular}


Table 3: Rating and Outlook Revision Effort

This table reports mean number of rating reviews per tranche within a given year. Rating actions include rating revisions (upgrade, downgrade, confirmed) and outlook revisions (positive, negative, stable). Revision effort is further segmented according to rating agency and number of assigned ratings. Statistical significance levels for differences in means are reported as results of a two-sample t-test. ***, **, and * denote significance at the $1 \%, 5 \%$, and $10 \%$ confidence level.

\begin{tabular}{|c|c|c|c|c|c|c|c|c|c|c|c|}
\hline \multirow{2}{*}{ Year } & \multicolumn{5}{|c|}{ Single-rated Tranches } & \multicolumn{5}{|c|}{ Multiple-rated Tranches } & \multirow{2}{*}{$\begin{array}{c}\text { Diff } \\
\left(M_{M}-M_{S}\right)\end{array}$} \\
\hline & $\mathrm{N}$ & $\begin{array}{c}\text { Mean } \\
\left(\mathrm{M}_{\mathrm{S}}\right)\end{array}$ & SD & Min & Max & $\mathrm{N}$ & $\begin{array}{c}\text { Mean } \\
\left(\mathrm{M}_{\mathrm{M}}\right)\end{array}$ & SD & Min & Max & \\
\hline \multicolumn{12}{|c|}{ Panel A: S\&P } \\
\hline 2000 & $4^{\prime} 473$ & 0.180 & 0.404 & 0 & 3 & $16^{\prime} 408$ & 0.248 & 0.593 & 0 & 8 & $0.068 * * *$ \\
\hline 2001 & 4'372 & 0.045 & 0.227 & 0 & 3 & $19 ' 017$ & 0.053 & 0.244 & 0 & 4 & $0.008^{*}$ \\
\hline 2002 & 4'807 & 0.037 & 0.235 & 0 & 10 & $23 ' 757$ & 0.092 & 0.458 & 0 & 7 & $0.055^{* * *}$ \\
\hline 2003 & 6'112 & 0.069 & 0.272 & 0 & 4 & 31'614 & 0.111 & 0.333 & 0 & 6 & $0.041^{* * *}$ \\
\hline 2004 & $7^{\prime} 745$ & 0.062 & 0.264 & 0 & 5 & $36^{\prime} 473$ & 0.112 & 0.460 & 0 & 10 & $0.049 * * *$ \\
\hline 2005 & 9'823 & 0.050 & 0.234 & 0 & 8 & $466^{\prime} 685$ & 0.089 & 0.289 & 0 & 3 & $0.038 * * *$ \\
\hline 2006 & $11^{\prime} 491$ & 0.047 & 0.262 & 0 & 4 & 62'159 & 0.105 & 0.353 & 0 & 10 & $0.058 * * *$ \\
\hline 2007 & 13'109 & 0.369 & 0.984 & 0 & 9 & 74'103 & 0.298 & 0.859 & 0 & 11 & $-0.071 * * *$ \\
\hline 2008 & 13'357 & 0.895 & 1.625 & 0 & 10 & $72 ' 791$ & 1.099 & 1.931 & 0 & 10 & $0.204^{* * *}$ \\
\hline 2009 & $14 ' 132$ & 1.249 & 1.484 & 0 & 9 & $70 ' 830$ & 1.695 & 1.778 & 0 & 8 & $0.446^{* * *}$ \\
\hline 2010 & $15^{\prime} 684$ & 0.618 & 1.065 & 0 & 6 & $68 ' 714$ & 0.756 & 1.255 & 0 & 6 & $0.138^{* * *}$ \\
\hline 2011 & 15'348 & 0.475 & 0.866 & 0 & 8 & $67^{\prime} 424$ & 0.673 & 1.296 & 0 & 8 & $0.198 * * *$ \\
\hline \multicolumn{12}{|c|}{ Panel B: Moody's } \\
\hline 2000 & 1'502 & 0.029 & 0.169 & 0 & 1 & $12^{\prime} 587$ & 0.034 & 0.194 & 0 & 3 & 0.005 \\
\hline 2001 & 1'802 & 0.001 & 0.024 & 0 & 1 & $15^{\prime} 111$ & 0.043 & 0.203 & 0 & 1 & $0.043^{* * *}$ \\
\hline 2002 & 2'186 & 0.012 & 0.108 & 0 & 1 & $18^{\prime} 702$ & 0.133 & 0.356 & 0 & 4 & $0.121^{* * *}$ \\
\hline 2003 & 2'122 & 0.057 & 0.270 & 0 & 2 & $23 ' 787$ & 0.178 & 0.405 & 0 & 2 & $0.121^{* * *}$ \\
\hline 2004 & 1'642 & 0.112 & 0.444 & 0 & 2 & $28 ' 750$ & 0.253 & 0.477 & 0 & 3 & $0.141^{* * *}$ \\
\hline 2005 & 1'405 & 0.157 & 0.584 & 0 & 4 & 40'390 & 0.279 & 0.478 & 0 & 6 & $0.122 * * *$ \\
\hline 2006 & 1'335 & 0.072 & 0.330 & 0 & 3 & $56 ' 161$ & 0.162 & 0.400 & 0 & 4 & $0.090 * * *$ \\
\hline 2007 & 1'399 & 0.084 & 0.320 & 0 & 2 & $65 ' 850$ & 0.261 & 0.579 & 0 & 6 & $0.178 * * *$ \\
\hline 2008 & 1'358 & 0.588 & 0.967 & 0 & 5 & $64 ' 844$ & 0.819 & 1.098 & 0 & 8 & $0.231^{* * *}$ \\
\hline 2009 & 1'333 & 0.638 & 0.674 & 0 & 3 & 63'189 & 0.895 & 0.893 & 0 & 5 & $0.257 * * *$ \\
\hline 2010 & 1'305 & 0.270 & 0.516 & 0 & 2 & 61'295 & 0.839 & 0.835 & 0 & 4 & $0.569 * * *$ \\
\hline 2011 & 1'179 & 0.417 & 0.556 & 0 & 2 & 60'611 & 0.220 & 0.444 & 0 & 4 & $-0.198 * * *$ \\
\hline \multicolumn{12}{|c|}{ Panel C: Fitch } \\
\hline 2000 & 4'101 & 0.049 & 0.334 & 0 & 6 & $16^{\prime} 808$ & 0.036 & 0.372 & 0 & 6 & $-0.013^{* *}$ \\
\hline 2001 & 4'813 & 0.145 & 0.434 & 0 & 5 & $19 ' 580$ & 0.032 & 0.209 & 0 & 4 & $-0.112 * * *$ \\
\hline 2002 & $5^{\prime} 041$ & 0.548 & 0.584 & 0 & 5 & $22 ' 768$ & 0.101 & 0.496 & 0 & 7 & $-0.447 * * *$ \\
\hline 2003 & 4'992 & 0.726 & 0.595 & 0 & 5 & 28'165 & 0.345 & 0.576 & 0 & 6 & $-0.381 * * *$ \\
\hline 2004 & 3'178 & 0.467 & 0.633 & 0 & 5 & $26^{\prime} 968$ & 0.338 & 0.547 & 0 & 5 & $-0.129 * * *$ \\
\hline 2005 & $2^{\prime} 428$ & 0.320 & 0.678 & 0 & 7 & 29'532 & 0.324 & 0.548 & 0 & 4 & 0.004 \\
\hline 2006 & 3'237 & 0.384 & 0.734 & 0 & 10 & $36 ' 963$ & 0.499 & 0.589 & 0 & 5 & $0.114^{* * *}$ \\
\hline 2007 & 4'155 & 0.703 & 0.983 & 0 & 9 & $44 ' 229$ & 0.847 & 0.973 & 0 & 9 & $0.144 * * *$ \\
\hline 2008 & 4'173 & 2.744 & 2.326 & 0 & 10 & 43'958 & 2.121 & 1.978 & 0 & 11 & $-0.623 * * *$ \\
\hline 2009 & $5^{\prime} 201$ & 1.853 & 1.040 & 0 & 10 & $43^{\prime} 436$ & 2.080 & 1.474 & 0 & 10 & $0.227 * * *$ \\
\hline 2010 & 5'305 & 1.802 & 1.112 & 0 & 6 & $42^{\prime} 506$ & 1.216 & 0.852 & 0 & 6 & $-0.586 * * *$ \\
\hline 2011 & 5'197 & 3.129 & 1.134 & 0 & 8 & $41^{\prime} 686$ & 2.598 & 2.039 & 0 & 10 & $-0.532 * * *$ \\
\hline
\end{tabular}




\section{Table 4.1: S\&P Rating Revision Activity Regression}

This table provides the results of the fixed effects multiple linear regression for rating revision activity of single- and multiple-rated tranches. The dependent variable is $S \& P$ Revision Activity and refers to the number of credit rating reviews (upgrade, downgrade, confirmed) performed by S\&P per tranche and calendar year. Multiple Ratings is a dichotomous variable coded 1 if a tranche is rated by more than one rating agency and 0 otherwise. Triple Rating is dichotomous and identifies tranches rated by all three rating agencies. We employ fixed effects at issuer-, year, and tranche vintage-level to control for unobserved heterogeneity. All other control variables are defined in the main text. In addition to rating revisions, (2) also includes watch list revisions (positive, negative, stable). In (3) we run the regression over a subsample including only tranches which eventually defaulted at some point in time. The sample specification in (5) corresponds to Lugo, Croce \& Faff (2014), including only multiple-rated tranches between 2002 and 2008. Cluster-robust standard errors are a clustered version of Huber-White sandwich estimators and account for potential clusters on tranche level.

\begin{tabular}{|c|c|c|c|c|}
\hline $\begin{array}{l}\text { Dependent: } \\
\text { S\&P Revision Activity }\end{array}$ & $\begin{array}{c}\text { (1) } \\
\text { Rating Activity }\end{array}$ & $\begin{array}{l}\text { (2) } \\
\text { Rating and Watch } \\
\text { List Activity }\end{array}$ & $\begin{array}{l}\text { (3) } \\
\text { Rating Activity } \\
\text { (Defaults) }\end{array}$ & $\begin{array}{c}\text { (4) } \\
\text { Multiple Ratings } \\
\text { (2002 - 2008) }\end{array}$ \\
\hline Multiple Ratings & $\begin{array}{l}0.0305 * * * \\
(0.00198)\end{array}$ & $\begin{array}{l}0.0196 * * * \\
(0.00336)\end{array}$ & $\begin{array}{l}0.1109 * * * \\
(0.00378)\end{array}$ & - \\
\hline Triple Rating & - & - & - & $\begin{array}{l}0.0464 * * * \\
(0.00318)\end{array}$ \\
\hline Controls & Yes & Yes & Yes & Yes \\
\hline Issuer-fixed effects & Yes & Yes & Yes & Yes \\
\hline Year-fixed effects & Yes & Yes & Yes & Yes \\
\hline Vintage-fixed effects & Yes & Yes & Yes & Yes \\
\hline Method & MLR & MLR & MLR & MLR \\
\hline McFadden's adj. $\mathrm{R}^{2}$ & 0.296 & 0.277 & 0.335 & 0.409 \\
\hline Observations & 803'865 & 803'865 & 284'960 & $298 ' 478$ \\
\hline
\end{tabular}

Cluster-robust standard errors in parentheses, ${ }^{* * *} \mathrm{p}<0.01,{ }^{* *} \mathrm{p}<0.05,{ }^{*} \mathrm{p}<0.1$ 


\section{Table 4.2: Moody's Rating Revision Activity Regression}

This table provides the results of the fixed effects multiple linear regression for rating revision activity of single- and multiple-rated tranches. The dependent variable is Moody's Revision Activity and refers to the number of credit rating reviews (upgrade, downgrade, confirmed) performed by Moody's per tranche and calendar year. Multiple Ratings is a dichotomous variable coded 1 if a tranche is rated by more than one rating agency and 0 otherwise. Triple Rating is dichotomous and identifies tranches rated by all three rating agencies. We employ fixed effects at issuer-, year, and tranche vintage-level to control for unobserved heterogeneity. All other control variables are defined in the main text. In addition to rating revisions, (2) also includes watch list revisions (positive, negative, stable). In (3) we run the regression over a subsample including only tranches which eventually defaulted at some point in time. The sample specification in (4) corresponds to Lugo, Croce \& Faff (2014), including only multiple-rated tranches between 2002 and 2008. Cluster-robust standard errors are a clustered version of Huber-White sandwich estimators and account for potential clusters on tranche level.

\section{Dependent:}

Moody's Revision Activity
$(1)$

(2)

Rating Activity Rating and Watch
Rating Activity Multiple Ratings List Activity
(3)

(4) (Defaults)

\begin{tabular}{|c|c|c|c|c|}
\hline Multiple Ratings & $\begin{array}{c}0.0376 * * * \\
(0.00234)\end{array}$ & $\begin{array}{c}0.0181 * * * \\
(0.00326)\end{array}$ & $\begin{array}{l}0.0872 * * * \\
(0.00653)\end{array}$ & - \\
\hline Triple Rating & - & - & - & $\begin{array}{c}0.0406 * * * \\
(0.00278)\end{array}$ \\
\hline Deal Complexity & $\begin{array}{c}-0.0004 * * * \\
(0.00007)\end{array}$ & $\begin{array}{c}-0.0009 * * * \\
(0.00011)\end{array}$ & $\begin{array}{l}0.0004^{* *} \\
(0.00019)\end{array}$ & $\begin{array}{c}-0.0004^{* * *} \\
(0.00010)\end{array}$ \\
\hline Controls & Yes & Yes & Yes & Yes \\
\hline Issuer-fixed effects & Yes & Yes & Yes & Yes \\
\hline Year-fixed effects & Yes & Yes & Yes & Yes \\
\hline Vintage-fixed effects & Yes & Yes & Yes & Yes \\
\hline Method & MLR & MLR & MLR & MLR \\
\hline McFadden's adj. $\mathrm{R}^{2}$ & 0.237 & 0.266 & 0.325 & 0.409 \\
\hline Observations & $602 ' 781$ & $602 ' 781$ & 219'396 & 257'645 \\
\hline
\end{tabular}

Cluster-robust standard errors in parentheses, ${ }^{* * *} \mathrm{p}<0.01,{ }^{* *} \mathrm{p}<0.05,{ }^{*} \mathrm{p}<0.1$ 


\section{Table 4.3: Fitch Rating Revision Activity Regression}

This table provides the results of the fixed effects multiple linear regression for rating revision activity of single- and multiple-rated tranches. The dependent variable is Fitch Revision Activity and refers to the number of credit rating reviews (upgrade, downgrade, confirmed) performed by Fitch per tranche and calendar year. Multiple Ratings is a dichotomous variable coded 1 if a tranche is rated by more than one rating agency and 0 otherwise. Triple Rating is dichotomous and identifies tranches rated by all three rating agencies. We employ fixed effects at issuer-, year-, and tranche vintage-level to control for unobserved heterogeneity. All other control variables are defined in the main text. In addition to rating revisions, (2) also includes watch list revisions (positive, negative, stable). In (3) we run the regression over a subsample including only tranches which eventually defaulted at some point in time. The sample specification in (4) corresponds to Lugo, Croce \& Faff (2014), including only multiple-rated tranches between 2002 and 2008. Cluster-robust standard errors are a clustered version of Huber-White sandwich estimators and account for potential clusters on tranche level.

\begin{tabular}{|c|c|c|c|c|}
\hline $\begin{array}{l}\text { Dependent: } \\
\text { Fitch Revision Activity }\end{array}$ & $\begin{array}{c}\text { (1) } \\
\text { Rating Activity }\end{array}$ & $\begin{array}{l}\text { (2) } \\
\text { Rating and Watch } \\
\text { List Activity }\end{array}$ & $\begin{array}{l}\text { (3) } \\
\text { Rating Activity } \\
\text { (Defaults) }\end{array}$ & $\begin{array}{c}\text { (4) } \\
\text { Multiple Ratings } \\
\text { (2002 - 2008) }\end{array}$ \\
\hline Multiple Ratings & $\begin{array}{c}0.0033 \\
(0.00384)\end{array}$ & $\begin{array}{l}0.0287 * * * \\
(0.00640)\end{array}$ & $\begin{array}{l}0.0399 * * * \\
(0.00474)\end{array}$ & - \\
\hline Triple Rating & - & - & - & $\begin{array}{c}0.0053 \\
(0.00520)\end{array}$ \\
\hline Controls & Yes & Yes & Yes & Yes \\
\hline Issuer-fixed effects & Yes & Yes & Yes & Yes \\
\hline Year-fixed effects & No & No & No & No \\
\hline Vintage-fixed effects & No & No & No & No \\
\hline Method & MLR & MLR & MLR & MLR \\
\hline McFadden's adj. $\mathrm{R}^{2}$ & 0.305 & 0.221 & 0.108 & 0.229 \\
\hline Observations & $455^{\prime} 272$ & $455^{\prime} 272$ & 151'367 & $192 ' 512$ \\
\hline
\end{tabular}

Cluster-robust standard errors in parentheses, *** $\mathrm{p}<0.01,{ }^{* *} \mathrm{p}<0.05, * \mathrm{p}<0.1$ 
Table 5: Receiver Operating Characteristics (ROC) for Rating Classification Accuracy

This table provides the covariate-adjusted receiver operating characteristic (AROC) estimation for different combinations of subsamples. In particular, the reported coefficients refer to the effect of multiple ratings on the area under the AROC curve (AAUC) for each rating agency. The logistic model is fit using maximum likelihood estimation and the binary reference variable is Default, assuming 1 if a tranche is in default at the end of a given prediction period and 0 otherwise. The classification variable is Tranche Rating, denoting the numerical credit rating of the respective rating agency at the beginning of a given year. We employ fixed effects at issuer- and tranche vintage-level to control for unobserved heterogeneity. All other control variables are defied in the main text. Robust standard errors based on Huber-White sandwich estimators are reported in brackets. Statistical significance of $\triangle$ AAUC are obtained by a chi-squared test. ***, **, and * denote significance at the $1 \%, 5 \%$, and $10 \%$ confidence level.

\begin{tabular}{|c|c|c|c|c|c|c|c|c|c|c|c|c|}
\hline \multirow{2}{*}{ Rating Date } & \multirow{2}{*}{$\begin{array}{l}\text { Prediction } \\
\text { Period }\end{array}$} & \multirow{2}{*}{$\begin{array}{r}\text { \# of Rated } \\
\text { Tranches }\end{array}$} & \multirow{2}{*}{$\begin{array}{r}\text { \# of } \\
\text { Defaults }\end{array}$} & \multicolumn{4}{|c|}{ Single-rated Tranches } & \multicolumn{4}{|c|}{ Multiple-rated Tranches } & \multirow{2}{*}{$\triangle \mathrm{AAUC}$} \\
\hline & & & & Tranches & Defaults & AAUC $_{\mathrm{i}, \mathrm{t}}$ & Std. Err. & Tranches & Defaults & AAUC $_{\mathrm{i}, \mathrm{t}}$ & Std. Err. & \\
\hline \multicolumn{13}{|c|}{ Panel A: S\&P } \\
\hline \multirow{2}{*}{ 01/2007 } & 1 Year & $60 ' 785$ & $0.51 \%$ & 9'042 & $0.66 \%$ & 0.887 & 0.0133 & $51 ' 743$ & $0.49 \%$ & 0.974 & 0.0029 & $0.087 * * *$ \\
\hline & 2 Years & $57^{\prime} 723$ & $3.87 \%$ & $8^{\prime} 745$ & $6.00 \%$ & 0.904 & 0.0053 & $48 ' 978$ & $3.49 \%$ & 0.967 & 0.0015 & $0.063^{* * *}$ \\
\hline \multirow{2}{*}{$01 / 2008$} & 1 Year & $69 ' 972$ & $3.55 \%$ & $10 ' 507$ & $5.44 \%$ & 0.916 & 0.0044 & $59 ' 465$ & $3.21 \%$ & 0.956 & 0.0020 & $0.040^{* * *}$ \\
\hline & 2 Years & 67'393 & $16.78 \%$ & $10^{\prime} 460$ & $24.46 \%$ & 0.816 & 0.0044 & $56 ' 933$ & $15.37 \%$ & 0.905 & 0.0016 & $0.089 * * *$ \\
\hline \multirow{2}{*}{ 01/2009 } & 1 Year & $68 ' 069$ & $16.64 \%$ & $11 ' 122$ & $23.16 \%$ & 0.843 & 0.0038 & $56 ' 947$ & $15.37 \%$ & 0.924 & 0.0013 & $0.081^{* * *}$ \\
\hline & 2 Years & 66'163 & $9.81 \%$ & $10^{\prime} 946$ & $11.41 \%$ & 0.688 & 0.0076 & $55 ' 217$ & $9.50 \%$ & 0.778 & 0.0028 & $0.089 * * *$ \\
\hline \multirow{2}{*}{$01 / 2010$} & 1 Year & $67 ' 215$ & $9.68 \%$ & $11 ' 967$ & $10.55 \%$ & 0.739 & 0.0065 & $55^{\prime} 248$ & $9.49 \%$ & 0.786 & 0.0024 & $0.047 * * *$ \\
\hline & 2 Years & $66^{\prime} 036$ & $7.67 \%$ & $11^{\prime} 846$ & $6.50 \%$ & 0.684 & 0.0084 & $54 ' 190$ & $7.93 \%$ & 0.709 & 0.0030 & $0.026 * *$ \\
\hline \multicolumn{13}{|c|}{ Panel B: Moody's } \\
\hline \multirow{2}{*}{ 01/2007 } & 1 Year & $46 ' 300$ & $1.68 \%$ & 1'143 & $0.00 \%$ & - & - & $45^{\prime} 157$ & $1.73 \%$ & 0.973 & 0.0016 & - \\
\hline & 2 Years & $44^{\prime} 619$ & $10.82 \%$ & 763 & 7.34\% & 0.857 & 0.0198 & $43^{\prime} 856$ & $10.89 \%$ & 0.945 & 0.0013 & $0.088^{* * *}$ \\
\hline \multirow{2}{*}{$01 / 2008$} & 1 Year & $53 ' 541$ & $12.28 \%$ & 903 & $7.97 \%$ & 0.862 & 0.0191 & $52 ' 638$ & $12.35 \%$ & 0.936 & 0.0013 & $0.074 * * *$ \\
\hline & 2 Years & $51 ' 729$ & $16.68 \%$ & $1^{\prime} 012$ & $34.19 \%$ & 0.903 & 0.0096 & $50 ' 717$ & $16.33 \%$ & 0.807 & 0.0024 & $-0.095 * * *$ \\
\hline \multirow{2}{*}{ 01/2009 } & 1 Year & $51 ' 900$ & $16.66 \%$ & $1^{\prime} 030$ & $34.17 \%$ & 0.909 & 0.0093 & $50 ' 870$ & $16.30 \%$ & 0.854 & 0.0020 & $-0.055^{* * *}$ \\
\hline & 2 Years & 49'374 & $10.09 \%$ & 597 & $5.53 \%$ & 0.879 & 0.0410 & $48 ' 777$ & $10.14 \%$ & 0.747 & 0.0030 & $-0.132 * * *$ \\
\hline \multirow{2}{*}{ 01/2010 } & 1 Year & $49 ' 375$ & $10.09 \%$ & 597 & $5.53 \%$ & 0.873 & 0.0306 & $48 ' 778$ & $10.14 \%$ & 0.747 & 0.0030 & $-0.126^{* * *}$ \\
\hline & 2 Years & $48^{\prime} 920$ & $4.36 \%$ & 806 & $11.54 \%$ & 0.877 & 0.0189 & $48 ' 114$ & $4.24 \%$ & 0.886 & 0.0048 & 0.009 \\
\hline \multicolumn{13}{|c|}{ Panel C: Fitch } \\
\hline \multirow{2}{*}{ 01/2007 } & 1 Year & $30^{\prime} 751$ & $2.03 \%$ & 2'928 & $6.28 \%$ & 0.952 & 0.0055 & $27^{\prime} 823$ & $1.59 \%$ & 0.953 & 0.0027 & 0.001 \\
\hline & 2 Years & $30 ' 800$ & $9.18 \%$ & $2^{\prime} 970$ & $30.37 \%$ & 0.890 & 0.0061 & $27 ' 830$ & $6.92 \%$ & 0.940 & 0.0020 & $0.050 * * *$ \\
\hline \multirow{2}{*}{ 01/2008 } & 1 Year & $36 ' 575$ & $9.98 \%$ & $3 ' 803$ & $33.45 \%$ & 0.883 & 0.0057 & $32 ' 772$ & $7.26 \%$ & 0.940 & 0.0019 & $0.057 * * *$ \\
\hline & 2 Years & $35 ' 741$ & $20.79 \%$ & 3'878 & $36.41 \%$ & 0.801 & 0.0073 & $31 ' 863$ & $18.89 \%$ & 0.812 & 0.0025 & 0.012 \\
\hline \multirow[b]{2}{*}{ 01/2009 } & 1 Year & $35 ' 906$ & $20.74 \%$ & 3'888 & $36.32 \%$ & 0.795 & 0.0076 & $32 ' 018$ & $18.85 \%$ & 0.876 & 0.0020 & $0.081^{* * *}$ \\
\hline & 2 Years & $35^{\prime} 087$ & $12.69 \%$ & 3'865 & $8.87 \%$ & 0.825 & 0.0098 & $31 ' 222$ & $13.16 \%$ & 0.725 & 0.0043 & $-0.100 * * *$ \\
\hline \multirow{2}{*}{$01 / 2010$} & 1 Year & $35 ' 087$ & $12.69 \%$ & $3 ' 865$ & $8.87 \%$ & 0.749 & 0.0132 & $31 ' 222$ & $13.16 \%$ & 0.800 & 0.0032 & $0.051 * * *$ \\
\hline & 2 Years & 34'159 & $7.85 \%$ & 3'692 & $3.17 \%$ & 0.749 & 0.0215 & $30 ' 467$ & $8.42 \%$ & 0.790 & 0.0045 & $0.041 *$ \\
\hline
\end{tabular}




\section{Table 6: Relative Tranche Size Regression}

This table provides the results of the fixed effects multiple linear regressions for the relationship between tranche size and multiple ratings for residential mortgage-backed securities rated by Moody's. The dependent variable is Tranche Size and refers to the natural logarithm of the tranche's original amount, denominated in USD. Multiple Ratings is dichotomous and coded one if a tranche is rated by more than one rating agency and zero otherwise. We control for Deal Size denoted as the natural logarithm of deal original amount, denominated in USD. We further control for unobserved heterogeneity by employing fixed effects at issuer and tranche vintage levels. The remaining variables are defined in the main text. Cluster-robust standard errors are a clustered version of Huber-White sandwich estimators and account for potential clusters on tranche level.

\begin{tabular}{|c|c|c|c|c|c|c|}
\hline \multirow{2}{*}{ Dependent: Tranche Size } & \multicolumn{6}{|c|}{ Rating at Issuance } \\
\hline & Aaa/Aa1/Aa2 & $\mathrm{Aa} 3 / \mathrm{A} 1 / \mathrm{A} 2$ & A3/Baa1/Baa2 & $\mathrm{Baa} 3 / \mathrm{Ba} 1 / \mathrm{Ba} 2$ & $\mathrm{Ba} 3 / \mathrm{B} 1 / \mathrm{B} 2$ & B3/Caa1/Caa2 \\
\hline \multirow[t]{2}{*}{ Multiple Ratings } & $0.5206^{* * *}$ & $0.3627^{* * *}$ & -0.0218 & 0.0731 & 0.1167 & $-0.0256^{* * *}$ \\
\hline & $(0.08703)$ & $(0.09956)$ & $(0.00000)$ & $(0.09103)$ & $(0.15839)$ & $(0.00365)$ \\
\hline \multirow[t]{2}{*}{ Deal Size } & $0.6251^{* * *}$ & $0.6138^{* * *}$ & 0.5712 & $0.5796 * * *$ & $0.3940^{* * *}$ & 0.0014 \\
\hline & $(0.02821)$ & $(0.02408)$ & $(0.00000)$ & $(0.03465)$ & $(0.13293)$ & $(0.05450)$ \\
\hline Controls & Yes & Yes & Yes & Yes & Yes & Yes \\
\hline Issuer-fixed effects & Yes & Yes & Yes & Yes & Yes & Yes \\
\hline Time-fixed effects & Yes & Yes & Yes & Yes & Yes & Yes \\
\hline Vintage level-fixed effects & Yes & Yes & Yes & Yes & Yes & Yes \\
\hline Method & MLR & MLR & MLR & MLR & MLR & MLR \\
\hline McFadden's adj. R ${ }^{2}$ & 0.131 & 0.590 & 0.618 & 0.662 & 0.595 & 0.903 \\
\hline Observations & 58'186 & 8'608 & 9'107 & 4'989 & 556 & 44 \\
\hline
\end{tabular}

Cluster-robust standard errors in parentheses, ${ }^{* * *} \mathrm{p}<0.01,{ }^{* *} \mathrm{p}<0.05,{ }^{*} \mathrm{p}<0.1$ 
Table 7: Rating Divergence of Multiple-rated Tranches

This table provides the results of the fixed effects negative binominal regression for rating divergence of multiple-rated tranches. The dependent variable is the rating gap and refers to the absolute value of the numerical rating notch difference between two rating agencies at each point in time. Tranche Age is a continuous variable denominated in months and indicates the time since the tranche has been issued. Triple Rating is binary and assumes 1 if a tranche has an additional third rating, and 0 otherwise. Tranche Seniority is binary and distinguishes senior tranches (1), which are typically rated AAA at inception, from for potential clusters on tranche level.

Dependent: Rating Gap

Tranche Age

Triple Rating

Tranche Seniority

Controls

Vintage-fixed effects

Method

McFadden's adj. $\mathrm{R}^{2}$

Observations

Cluster-robus standarderios in parenteses,
(1)

S\&P - Moody's S\&P - Moody's

(Total)

$0.067 * * *$

(0.0004)

$0.033^{* * *}$

(0.0117)

$-1.170 * * *$

(0.0139)

Yes

Yes

GLM

0.144

2'139'858

$05,{ }^{*} p<0.1$
(2)

(3)

(Pre-Crisis) S\&P - Fitch

$0.015^{* * *}$

(0.0007)

$0.124 * * *$

(0.0258)

$-2.478 * * *$

(0.0357)

Yes

Yes

0.190

1'138'932 (Total)

$0.093^{* * *}$

(0.0009)

$0.118 * * *$

(0.0201)

$-1.556^{* * *}$

(0.0261)

Yes

Yes

GLM

0.185

1'423'584
(4)

S\&P - Fitch (Pre-Crisis)

905'175

905'175

(0.0013)

0.059

(0.0587)

$-4.265^{* * *}$

(0.1317)

Yes

Yes

GLM
0.249

(6)

Moody's - Fitch Moody's - Fitch (Total) (Pre-Crisis)

(0.0006) $\quad(0.0009)$

$0.172 * * * \quad 0.547^{* * *}$

$(0.0191)$

$-1.393 * * *$

(0.0244) (0.0375)

Yes Yes

Yes Yes

GLM GLM

$0.149 \quad 0.229$

1'026'622

615'267 
Table 8: Average Marginal Effects of Tranche Age on pairwise Rating Gap

This table reports the average marginal effects (AME) calculated from the negative binominal regression model at selected values of the explanatory variables and averaging over the total sample (1985-2012). Additional model covariates are defined in the main text and include tranche size, remaining time to maturity, and a zero-one variable for collateral quality. The (-) indicates that the respective variables are held at their individual values for each observation.

\begin{tabular}{|c|c|c|c|c|c|c|c|c|c|}
\hline \multirow{2}{*}{$\begin{array}{l}\text { Tranche Age } \\
\text { (Months) }\end{array}$} & \multirow{2}{*}{$\begin{array}{l}\text { Triple Rating } \\
(1=\text { Yes, } 0=\text { No) }\end{array}$} & \multirow{2}{*}{$\begin{array}{l}\text { Seniority } \\
\text { (1=Senior, } \\
0=\text { Subrd.) }\end{array}$} & \multirow{2}{*}{$\begin{array}{l}\text { Vintage } \\
\text { (Years) }\end{array}$} & \multicolumn{2}{|c|}{$\begin{array}{c}\text { Rating Gap } \\
\text { S\&P/Moody's }\end{array}$} & \multicolumn{2}{|c|}{$\begin{array}{l}\text { Rating Gap } \\
\text { S\&P/Fitch }\end{array}$} & \multicolumn{2}{|c|}{$\begin{array}{c}\text { Rating Gap } \\
\text { Moody's/Fitch }\end{array}$} \\
\hline & & & & AME & Std. Err. & AME & Std. Err. & AME & Std. Err. \\
\hline 6 & - & - & - & $0.025 * * *$ & 0.0001 & $0.016 * * *$ & 0.0006 & $0.019 * * *$ & 0.0001 \\
\hline 12 & - & - & - & $0.038 * * *$ & 0.0002 & $0.028 * * *$ & 0.0010 & $0.028 * * *$ & 0.0002 \\
\hline 18 & - & - & - & $0.057 * * *$ & 0.0004 & $0.048^{* * *}$ & 0.0018 & $0.042 * * *$ & 0.0004 \\
\hline 24 & - & - & - & $0.086 * * *$ & 0.0008 & $0.081^{* * *}$ & 0.0033 & $0.062^{* * *}$ & 0.0008 \\
\hline 30 & - & - & - & $0.130 * * *$ & 0.0015 & $0.138 * * *$ & 0.0061 & $0.093 * * *$ & 0.0015 \\
\hline 36 & - & - & - & $0.196 * * *$ & 0.0028 & $0.235^{* * *}$ & 0.0111 & $0.139 * * *$ & 0.0027 \\
\hline 6 & 1 & - & - & $0.026 * * *$ & 0.0003 & $0.026 * * *$ & 0.0012 & $0.023^{* * *}$ & 0.0002 \\
\hline 12 & 1 & - & - & $0.039 * * *$ & 0.0004 & $0.044^{* * *}$ & 0.0022 & $0.035 * * *$ & 0.0003 \\
\hline 18 & 1 & - & - & $0.059 * * *$ & 0.0007 & $0.075 * * *$ & 0.0038 & $0.052 * * *$ & 0.0006 \\
\hline 24 & 1 & - & - & $0.090 * * *$ & 0.0011 & $0.127^{* * *}$ & 0.0068 & $0.078 * * *$ & 0.0011 \\
\hline 30 & 1 & - & - & $0.135^{* * *}$ & 0.0019 & $0.216^{* * *}$ & 0.0122 & $0.117^{* * *}$ & 0.0020 \\
\hline 36 & 1 & - & - & $0.204^{* * *}$ & 0.0033 & $0.368 * * *$ & 0.0219 & $0.174^{* * *}$ & 0.0035 \\
\hline 6 & 0 & - & - & $0.024 * * *$ & 0.0002 & $0.008^{* * *}$ & 0.0002 & $0.011^{* * *}$ & 0.0002 \\
\hline 12 & 0 & - & - & $0.037 * * *$ & 0.0003 & $0.014^{* * *}$ & 0.0003 & $0.016^{* * *}$ & 0.0003 \\
\hline 18 & 0 & - & - & $0.056 * * *$ & 0.0005 & $0.025 * * *$ & 0.0004 & $0.025 * * *$ & 0.0005 \\
\hline 24 & 0 & - & - & $0.084^{* * *}$ & 0.0009 & $0.042 * * *$ & 0.0008 & $0.037 * * *$ & 0.0007 \\
\hline 30 & 0 & - & - & $0.127 * * *$ & 0.0016 & $0.071^{* * *}$ & 0.0016 & $0.055^{* * *}$ & 0.0012 \\
\hline 36 & 0 & - & - & $0.192 * * *$ & 0.0029 & $0.121^{* * *}$ & 0.0030 & $0.082^{* * *}$ & 0.0020 \\
\hline 6 & - & 1 & - & $0.013^{* * *}$ & 0.0001 & $0.009 * * *$ & 0.0003 & $0.011^{* * *}$ & 0.0001 \\
\hline 12 & - & 1 & - & $0.020 * * *$ & 0.0002 & $0.015^{* * *}$ & 0.0004 & $0.017 * * *$ & 0.0002 \\
\hline 18 & - & 1 & - & $0.030 * * *$ & 0.0003 & $0.025 * * *$ & 0.0008 & $0.025^{* * *}$ & 0.0003 \\
\hline 24 & - & 1 & - & $0.045^{* * *}$ & 0.0005 & $0.042 * * *$ & 0.0014 & $0.038 * * *$ & 0.0006 \\
\hline 30 & - & 1 & - & $0.068 * * *$ & 0.0009 & $0.072 * * *$ & 0.0026 & $0.057^{* * *}$ & 0.0010 \\
\hline 36 & - & 1 & - & $0.102 * * *$ & 0.0016 & $0.122 * * *$ & 0.0048 & $0.085 * * *$ & 0.0018 \\
\hline 6 & - & 0 & - & $0.041^{* * *}$ & 0.0003 & $0.034^{* * *}$ & 0.0014 & $0.030 * * *$ & 0.0003 \\
\hline 12 & - & 0 & - & $0.062 * * *$ & 0.0004 & $0.057 * * *$ & 0.0025 & $0.045^{* * *}$ & 0.0005 \\
\hline 18 & - & 0 & - & $0.093 * * *$ & 0.0008 & $0.097 * * *$ & 0.0044 & $0.067^{* * *}$ & 0.0009 \\
\hline 24 & - & 0 & - & $0.140 * * *$ & 0.0015 & $0.166^{* * *}$ & 0.0080 & $0.100 * * *$ & 0.0016 \\
\hline 30 & - & 0 & - & $0.212^{* * *}$ & 0.0027 & $0.282^{* * *}$ & 0.0144 & $0.150 * * *$ & 0.0028 \\
\hline 36 & - & 0 & - & $0.320 * * *$ & 0.0048 & $0.480 * * *$ & 0.0260 & $0.224^{* * *}$ & 0.0048 \\
\hline 36 & - & - & $<2002$ & $0.047 * * *$ & 0.0010 & $0.040 * * *$ & 0.0009 & $0.066^{* * *}$ & 0.0017 \\
\hline 36 & - & - & 2002 & $0.132 * * *$ & 0.0020 & $0.088 * * *$ & 0.0047 & $0.132 * * *$ & 0.0028 \\
\hline 36 & - & - & 2003 & $0.148 * * *$ & 0.0022 & $0.142^{* * *}$ & 0.0037 & $0.147^{* * *}$ & 0.0030 \\
\hline 36 & - & - & 2004 & $0.183^{* * *}$ & 0.0026 & $0.257^{* * *}$ & 0.0108 & $0.154^{* * *}$ & 0.0031 \\
\hline 36 & - & - & 2005 & $0.207 * * *$ & 0.0029 & $0.316 * * *$ & 0.0107 & $0.160 * * *$ & 0.0032 \\
\hline 36 & - & - & 2006 & $0.268 * * *$ & 0.0040 & $0.401^{* * *}$ & 0.0220 & $0.174^{* * *}$ & 0.0034 \\
\hline 36 & - & - & 2007 & $0.301^{* * *}$ & 0.0047 & $0.489 * * *$ & 0.0426 & $0.199 * * *$ & 0.0043 \\
\hline
\end{tabular}



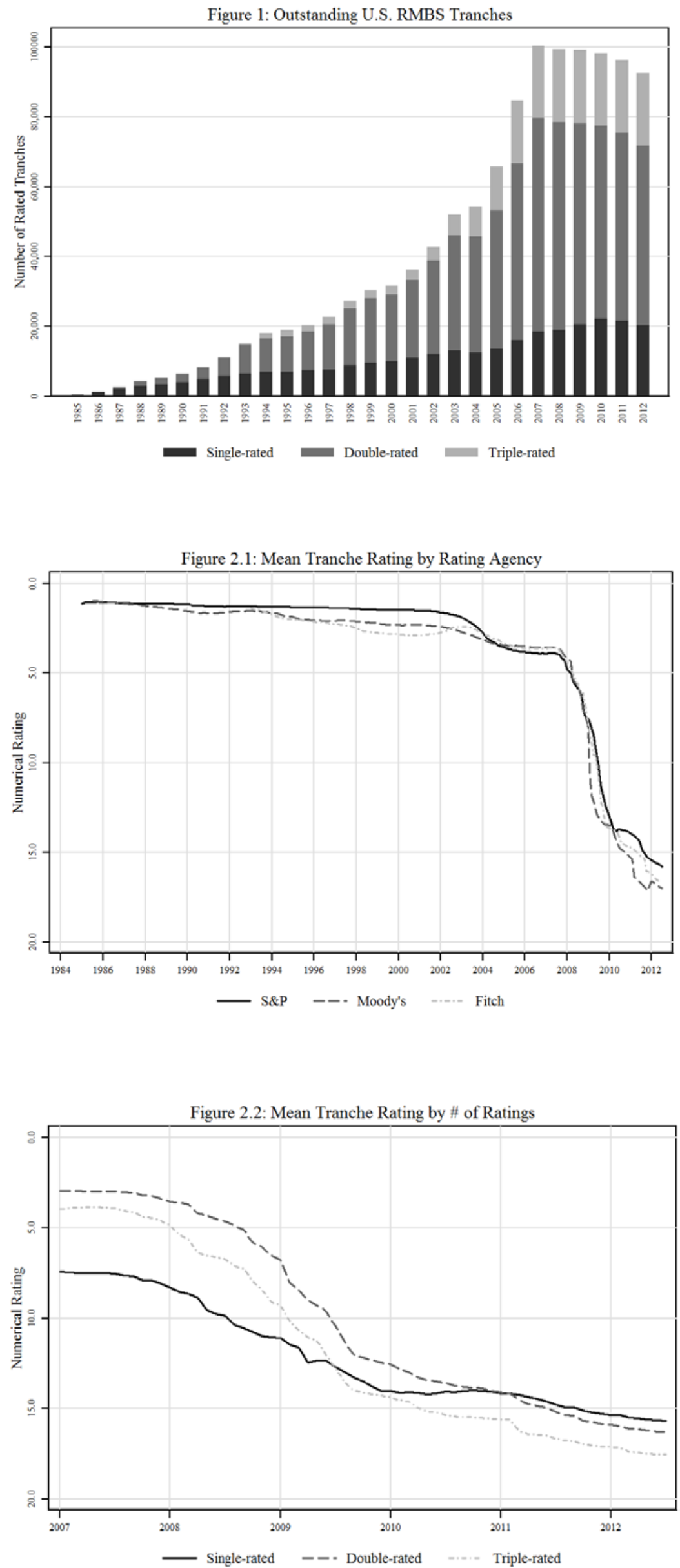
Figure 3.1: Predicted Number of Tranche Rating Reviews per Year (S\&P)

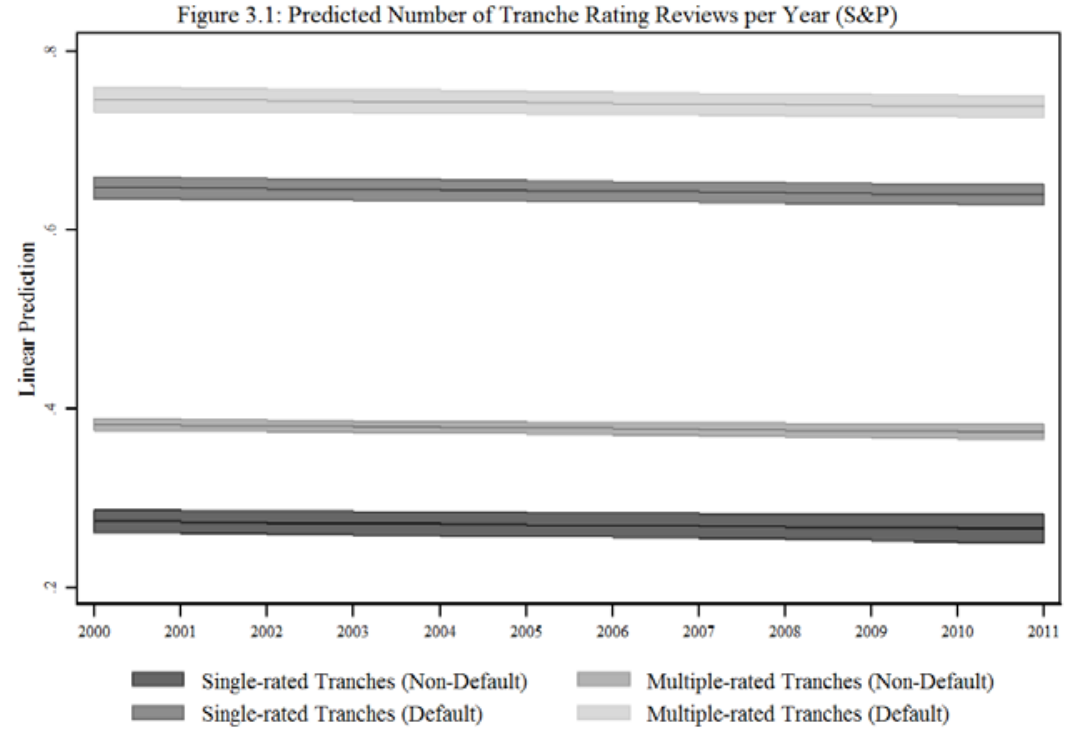

Figure 3.2: Predicted Number of Tranche Rating Reviews per Year (Moody's)
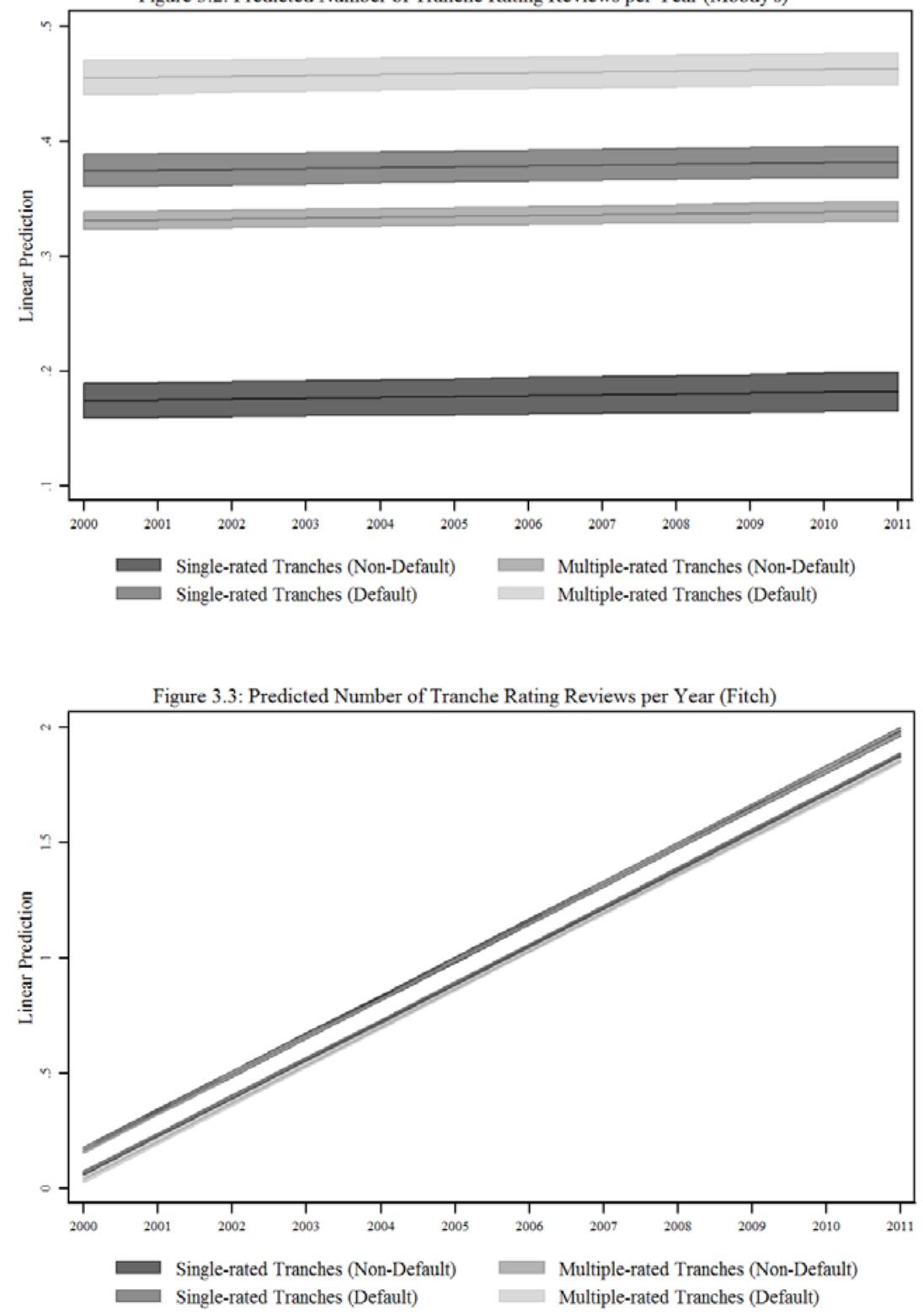
Figure 4.1: Predicted Number of Tranche Rating Reviews by Rating Class (S\&P)

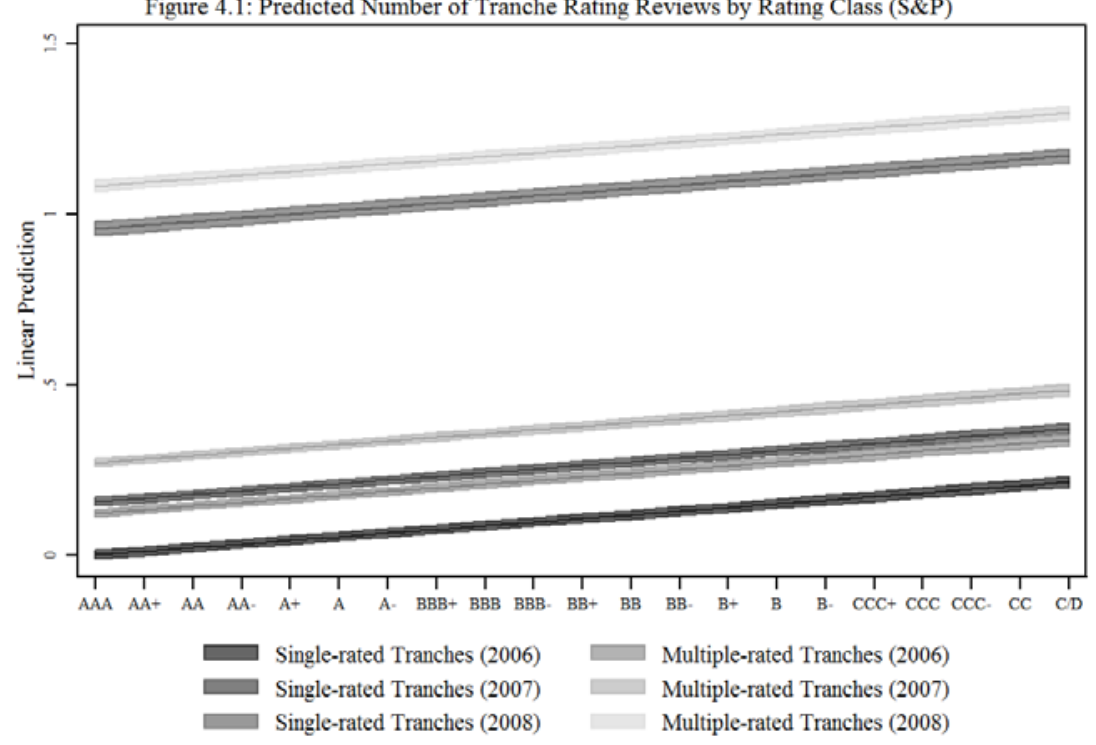

Figure 4.2: Predicted Number of Tranche Rating Reviews by Rating Class (Moody's)

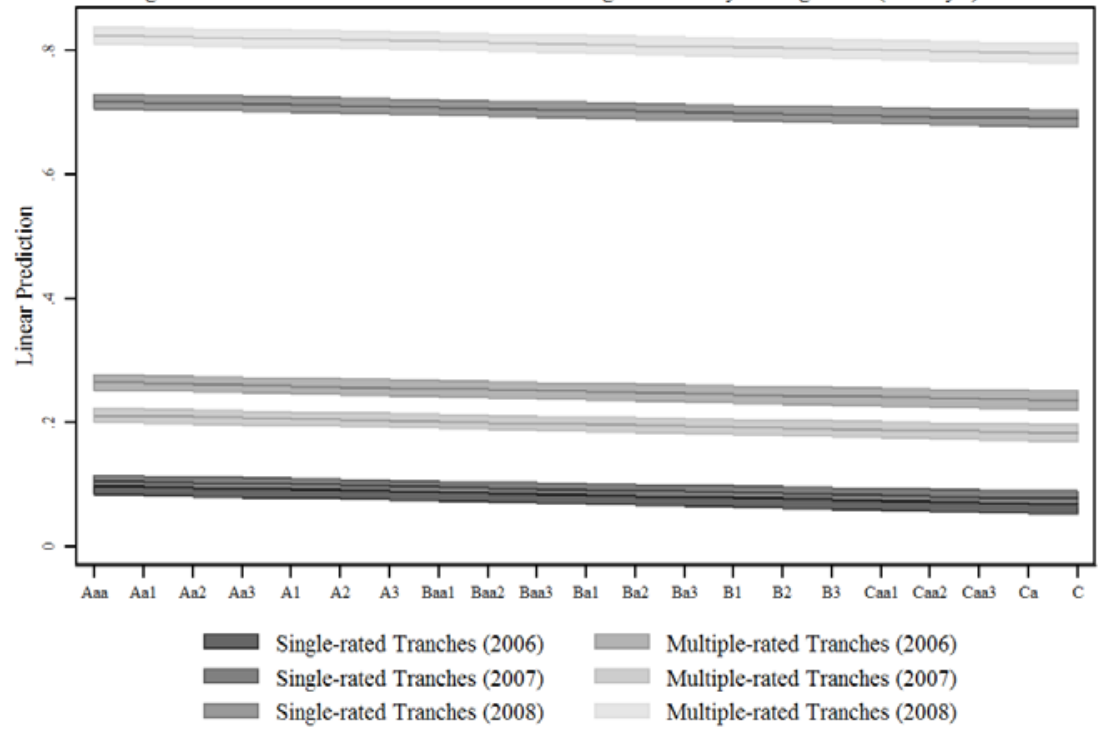

Figure 4.3: Predicted Number of Tranche Rating Reviews by Rating Class (Fitch)

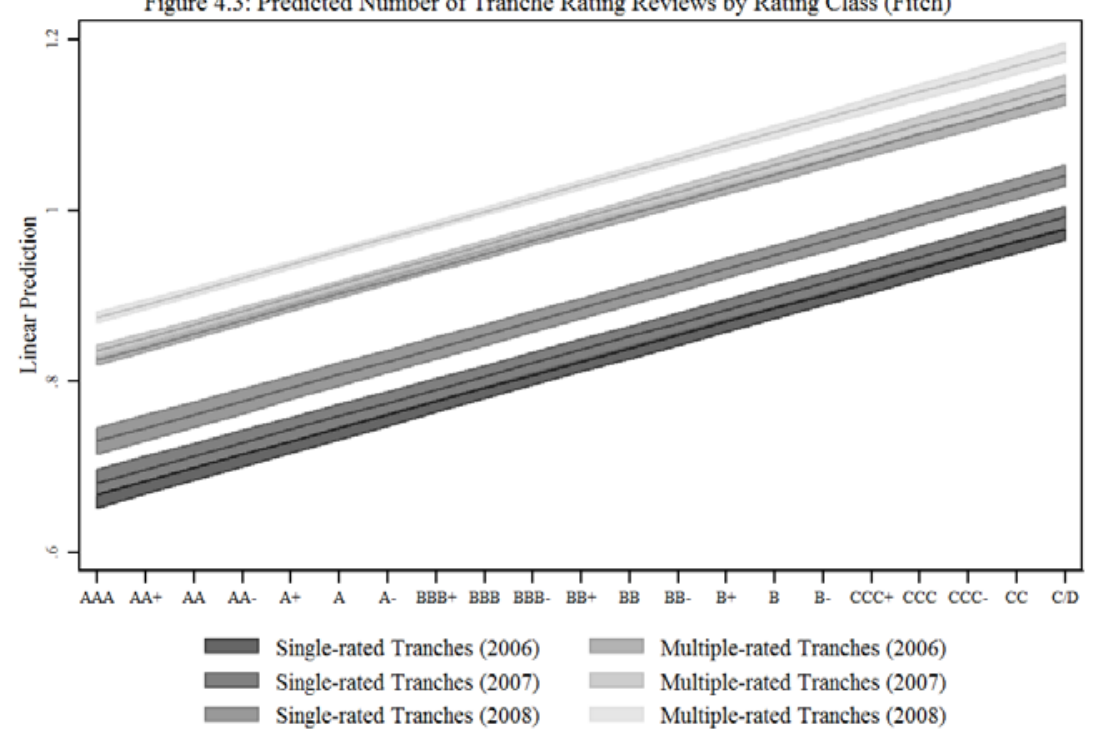



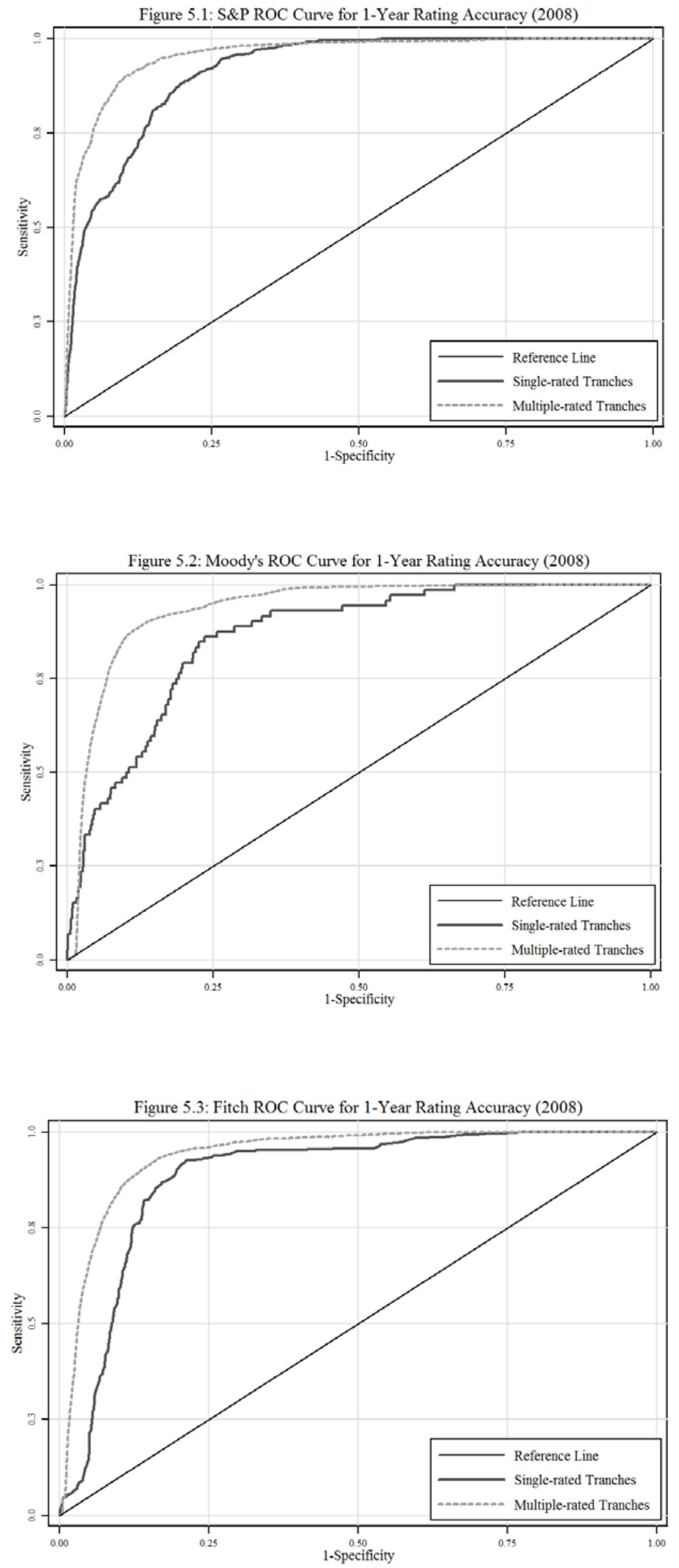


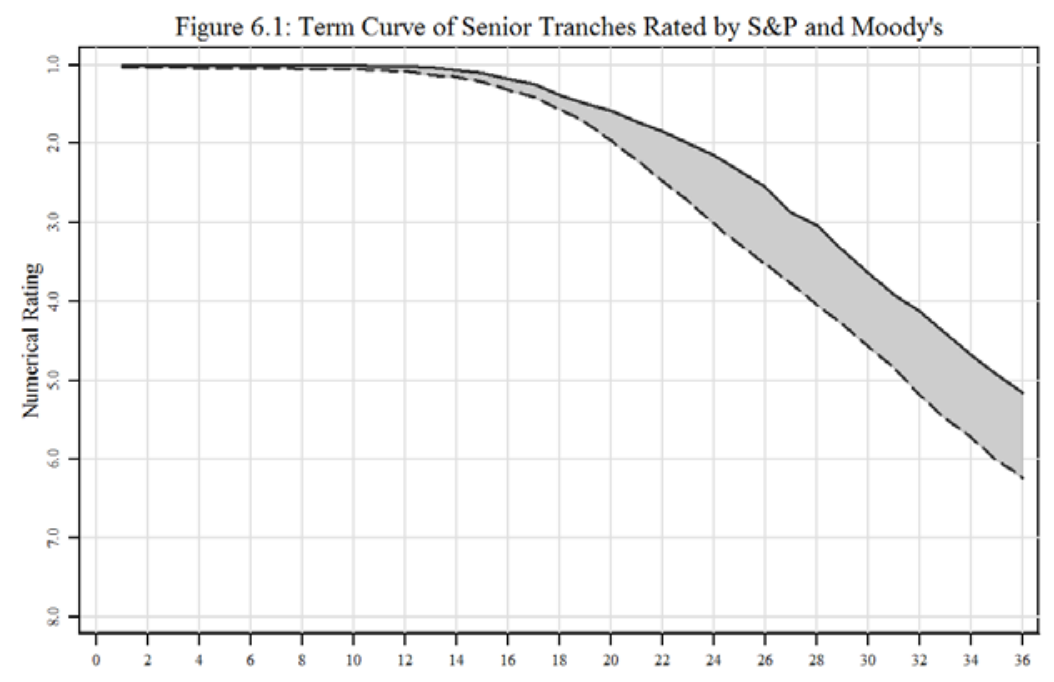

— Mean S\&P Rating - - - Mean Moody's Rating $\square$ Rating Notch Difference
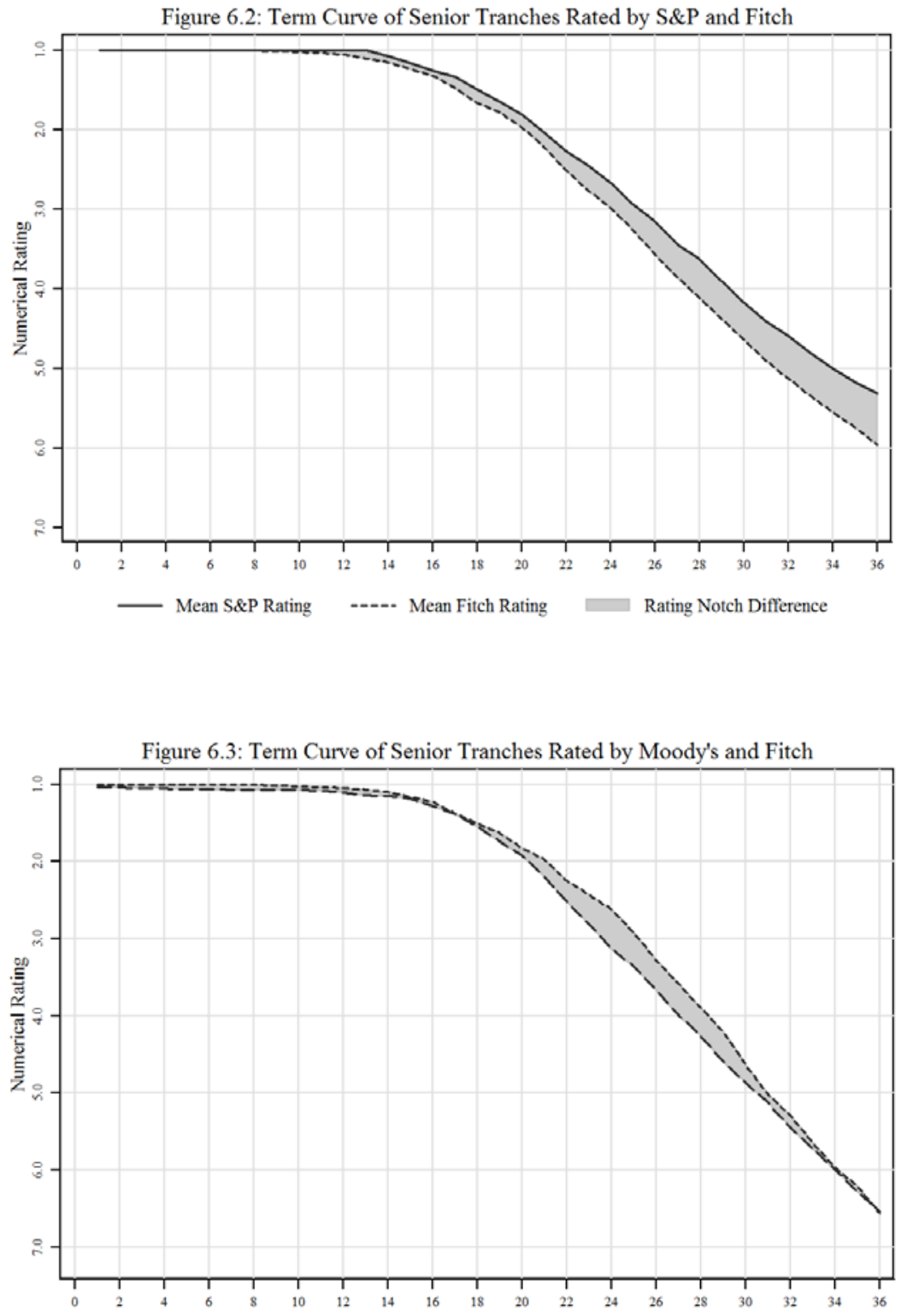

--- Mean Moody's Rating -.--. Mean Fitch Rating Rating Notch Difference 